FÁTIMA CRISTINA DE OLIVEIRA

SISTEMA MULTIESPECTRAL PORTÁTIL PARA MONITORAMENTO DE OXIGÊNIO DISSOLVIDO EM MEIOS AQUOSOS E DA DINÂMICA DE CRESCIMENTO MICROBIANO 
FÁTIMA CRISTINA DE OLIVEIRA

\title{
SISTEMA MULTIESPECTRAL PORTÁTIL PARA MONITORAMENTO DE OXIGÊNIO DISSOLVIDO EM MEIOS AQUOSOS E DA DINÂMICA DE CRESCIMENTO MICROBIANO
}

\author{
Dissertação apresentada à Escola \\ Politécnica da Universidade de São Paulo \\ para obtenção do título de Mestre em \\ Ciências. \\ Área de concentração: Microeletrônica \\ Orientador: Prof. Livre-Docente Walter \\ Jaimes Salcedo
}


Este exemplar foi revisado e corrigido em relação à versão original, sob responsabilidade única do autor e com a anuência de seu orientador.

São Paulo, de de

Assinatura do autor:

Assinatura do orientador:

Catalogação-na-publicação

Oliveira, Fátima Cristina de

SISTEMA MULTIESPECTRAL PORTÁTIL PARA MONITORAMENTO DE OXIGENIO DISSOLVIDO EM MEIOS AQUOSOS E DA DINÂMICA DE CRESCIMENTO MICROBIANO / F. C. Oliveira -- versão corr. -- São Paulo, 2017

$54 \mathrm{p}$.

Dissertação (Mestrado) - Escola Politécnica da Universidade de São Paulo. Departamento de Engenharia de Sistemas Eletrônicos.

1.oxigênio dissolvido 2.sensor de fibra óptica 3.octaetilporfirina de platina 4.sistema multiespectral portátil I.Universidade de São Paulo. Escola Politécnica. Departamento de Engenharia de Sistemas Eletrônicos II.t. 
Dedico este trabalho a minha avó Dona Esmeralda, amor infinito. 


\section{AGRADECIMENTOS}

Agradeço a Deus por ter guiado meus passos até aqui.

A minha avó, Esmeralda Evangelista de Oliveira, por ser a melhor avó que alguém poderia ter.

À minha mãe Maria Inês Costa de Oliveira, minha irmã Patrícia Koch, meu sobrinho Miguel Koch, meus tios Marizete Evangelista de Oliveira, Marco Antônio de Oliveira e Cleane Passos de Oliveira, por me apoiarem sempre.

Ao meu amor, Paulo de Toledo Ribeiro pela paciência, compreensão e amor dedicado durante estes anos.

À minha irmã de alma Isabella Franco Braga por todo apoio, amizade e carinho que tenho recebido durante todos estes anos, e pelo lindo presente chamado Sophia Franco Braga.

Ao grande ser humano Mauro Sérgio Braga pela amizade, companheirismo e troca de experiências, cuja a contribuição para a realização deste trabalho foi essencial. Obrigada meu irmão!

Aos amigos, Edison José de Aguiar Junior e Lucimara do Prado Martins pela convivência, amizade e pelo presente chamado Júlia Martins de Aguiar.

Aos técnicos do laboratório do CEPEMA -USP, Osmar Gomes, Marcela Galluzzi, Luciano Maia, Rui Azevedo, Rafaela Araújo, Nilson Roman pelo auxílio que me foi dado no laboratório durante o desenvolvimento deste trabalho.

Aos amigos da pós-graduação, Edmilson Braga, Hipólito Allan Champi, Rina Huamanrayne Bustamante, Walter Borysow, Daniel Amorim Augusto pelo apoio e contribuições para o trabalho.

Aos meus afilhados Antônio Leal de Almeida, Sophia Franco Braga e Júlia Martins de Aguiar, por me fazerem querer ser uma pessoa melhor a cada dia.

A todos muito obrigada! 


\section{RESUMO}

Nos dias de hoje o controle e monitoração de sistemas biológicos relacionados ao controle ambiental tem sido considerado importante para o diagnóstico e biorremediação de sistemas aquosos como rios e lagos. A eficácia dos processos de controle está diretamente relacionada aos processos de medição "in-situ" em tempo real. Nesse sentido o presente trabalho apresenta o desenvolvimento de sistemas multiespectrais portáteis para monitoramento, "in-situ" e em tempo real, da dinâmica do crescimento microbiano utilizados em processos de biorremediação. Assim, para este fim foram desenvolvidos dois sistemas, um para monitorar a concentração de oxigênio dissolvido (OD) em meio aquoso e outro para monitorar a absorção óptica do meio de cultura. O sensor óptico para monitorar a concentração de OD está baseado em uma fibra óptica na qual em uma de suas pontas (extremidades) foi depositado um filme fino de Poli (cloreto de vinila) ( $P V C$ ) dopado com moléculas de octaetilporfirina de platina (PtOEP) como parte sensível do dispositivo. O sensor mostrou resposta linear em regiões entre 4 e $18 \mathrm{mg} / \mathrm{L}$ de $\mathrm{OD}$ em meio aquoso, tendo como tempo de resposta de $8 \mathrm{~s}$ e tempo de recuperação de $236 \mathrm{~s}$. O sistema de medida de absorção óptica do meio de cultura foi projetado e fabricado utilizando-se um fotodetector multiespectral e um diodo LED $(600 \mathrm{~nm})$ como fonte de excitação. A aquisição, controle e processamento de sinais deste sistema está baseado em uma placa de aquisição NI modelo myRIO-1900 fabricado pela National Instruments, utilizando-se tecnologia Field Programmable Gate Array (FPGA). Os resultados obtidos com este sistema mostram ter o mesmo nível de desempenho se comparado ao de um sistema biofotométrico comercial na faixa de concentração entre $1,13 \mathrm{mg} / \mathrm{ml}$ à $2,11 \mathrm{mg} / \mathrm{ml}$.

Palavras-chave: oxigênio dissolvido, sensor de fibra óptica, octaetilporfirina de platina, sistema multiespectral portátil. 


\begin{abstract}
Nowadays, the controlling and monitoring biological systems related to environmental control has been considered important for the diagnosis and bio-remediation of aqueous systems like rivers and lakes. The effectiveness of this control processes are directly related to "in-situ" and real-time measurement processes. In this sense the present work presents the development of portable multispectral systems for monitoring, "in-situ" and in real time, the dynamics of microbial growth used in bioremediation processes. So, for this purpose were fabricated two systems, one to monitor the concentration of dissolved oxygen (DO) in aqueous medium and another to monitor the optical absorption of culture medium. The optical sensor to monitor the DO is based on an optical fiber in which in one of its ends was deposited a poly(vinyl chloride) (PVC) thin film doped with Platinum octaethylphorphyrin molecules (PtOEP) as part of the device. The sensor showed linear response in regions between 4 and 18 $\mathrm{mg} / \mathrm{L}$ of DO in aqueous medium, with response time of $8 \mathrm{~s}$ and the recovery time of 236s. The system of measurement of optical absorption of culture medium was designed and manufactured using a multispectral photodetector and a diode LED $(600 \mathrm{~nm})$ as a source of excitation. The acquisition, signal processing and control of this system are based on an acquisition card NI myRIO-1900 model manufactured by National Instruments, using FPGA technology. The results obtained with this system shows to have the same level of performance to that of a commercial biophotometric system in the concentration range of $1.13 \mathrm{mg} / \mathrm{mL}$ to $2.11 \mathrm{mg} / \mathrm{mL}$.
\end{abstract}

Keywords: Oxygen dissolved, Optical fiber sensor, Platinum octaethylphorphyrin, portable multispectral system. 


\section{LISTA DE FIGURAS}

Figura 1 - Representação esquemática do Eletrodo de Clark.

Figura 2 - Complexos de Platina e Paládio (a) Octaetilporfirina de Platina (PtOEP) (b) Octaetilporfirina de Paládio (PdOEP) .18

Figura 3- Contagem de células viáveis (MANDIGAN et al., 2016). 20

Figura 4- a) turbidez medida no espectrofotômetro. b) curva de crescimento de dois microorganismos, com diferentes taxas de crescimento. c) relação número de células ou peso seco e as medidas de turbidez (ALTERTHUM, 2008) .22

Figura 5- Gráfico representando a curva de crescimento microbiano. (ALTERTHUM, 2008).

Figura 6 -Diagrama esquemático do arranjo experimental para caracterização do fotodetector TCS3200 como sistema de medida de fotoluminescência. 30

Figura 7 - Diagrama esquemático do arranjo experimental de medida do OD. 32

Figura 8 - Diagrama esquemático do sistema utilizado para controlar a concentração de OD em água deionizada.

Figura 9 - Diagrama esquemático do sistema para controle de OD utilizado para análise da resposta dinâmica do sensor

Figura 10 - Sistema multiespectral portátil para monitoramento da taxa de crescimento bacteriano 36

Figura 11 - Curvas de respostas das matrizes de fotodiodos com filtros vermelho, verde e azul em função da concentração de OD.

Figura 12 - Derivada das curvas obtidas da curva de resposta (Figura 11) correspondente as matrizes de fotodiodo RGB 40

Figura 13 - Resposta dinâmica para o sensor de deteç̧ão de OD. 41

Figura 14 - A evolução do coeficiente de absorçãoem função do tempo de cultivo bacteriano, obtida através do biofotômetro e do sistema mutiespectral portátil. Como referência também é mostrada a evolução da massa seca bacteriana (medição direta) em função do tempo.

Figura 15 - Gráfico do coeficiente de absorbância em função da massa seca obtida a partir dos dados que foram retratados na Figura 14 
Figura 16 - Taxa de crescimento específico da cultura bacteriana em função da massa seca correspondente aos dados obtidos do biofotômetro, sistema multiespectral portátil e medição direta da massa seca, respectivamente.

Figura 17 - Diagrama esquemático de um sistema integrado para monitoramento da taxa de crescimento microbiano e oxigênio dissolvido em meio de cultura. 


\section{LISTA DE TABELAS}

Tabela 1 - Opções selecionáveis para fotodiodos: Seleção da região de frequência do sinal de saída 31

Tabela 2 -Seleção da frequência de saída: combinação binária de duas entradas digitais do circuito integrado S2 e S3 


\section{LISTA DE SÍMBOLOS, SIGLAS E ABREVIATURAS}

\begin{tabular}{|c|c|}
\hline Abs & Absorbância \\
\hline Ccel & Concentração celular \\
\hline CMOS & Conplementary Metal Oxide Semiconductor \\
\hline DOS & Bis( 2- ethylhexyl) sebacate \\
\hline FPGA & Field Programmable Gate Array \\
\hline FWHM & Full Width at Half Maximum \\
\hline lamostra & Corrente de fotodiodos com filtros centrado em $\lambda$, correspondendo \\
\hline & a luz transmitida através da amostra bacteriana \\
\hline Imeiodecultura & Corrente de fotodiodos, com filtro centrado em $\lambda$, correspondendo \\
\hline & a luz transmitida através da solução sem bactérias \\
\hline Ksv & Constante de Stern- Volmer \\
\hline$\lambda$ & Comprimento de onda \\
\hline LED & Diodo Emissor de Luz \\
\hline $\mathrm{mf}$ & Massa pesada antes da filtração \\
\hline $\mathrm{mi}$ & Massa pesada após a filtração \\
\hline $\mathrm{MO}$ & Matéria orgânica \\
\hline OD & Oxigênio dissolvido \\
\hline $\mathrm{PAHS}$ & Hidrocarbonetos aromáticos policíclicos \\
\hline PL & Fotoluminescência \\
\hline PtOEP & Octaetilporfirina de platina \\
\hline PtTFPP & Tetra (pentafluorfenil) porfirina de platina \\
\hline PVC & Poly (vinylchloride) - Poli(cloreto de vinila) \\
\hline PW & $\begin{array}{l}\text { Sinal de saída de intensidade luminosa do fotodiodo sem filtro do } \\
\text { sensor multiespectral da MaZet MMC6SCS }\end{array}$ \\
\hline RGB & Red, Green e Blue \\
\hline THF & Tetrahidrofurano \\
\hline UFC & Unidade Formadora de Colônias \\
\hline $\mathrm{vf}$ & Volume filtrado \\
\hline
\end{tabular}




\section{SUMÁRIO}

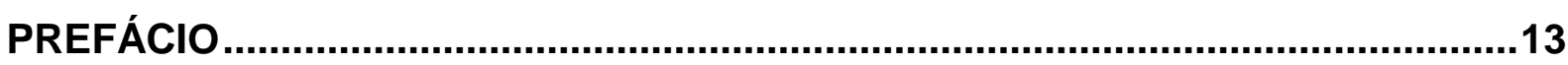

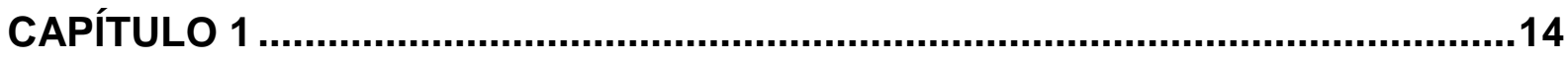

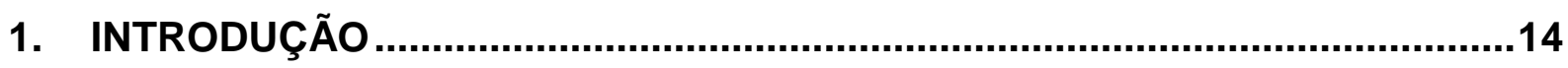

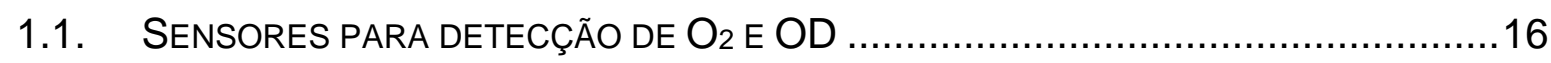

1.2. MÉTODOS PARA QUANTIFICAÇÃO DE CRESCIMENTO MICROBIANO .......................19

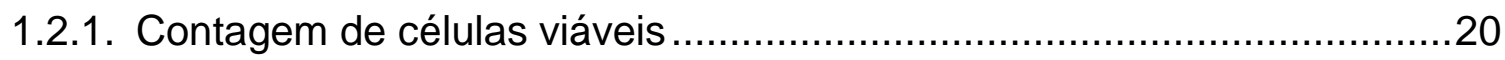

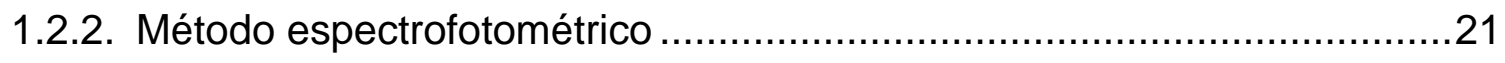

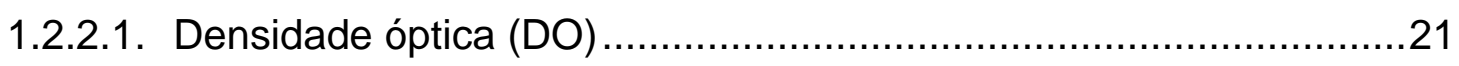

CAPÍTULO 2

2. OBJETIVOS

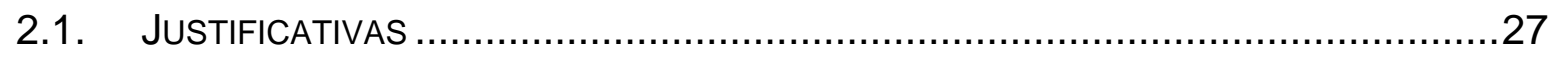

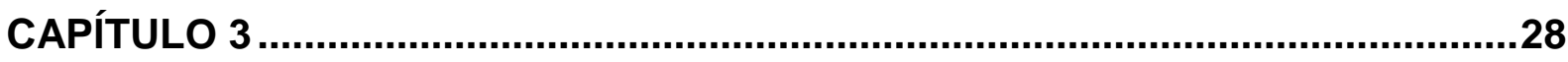

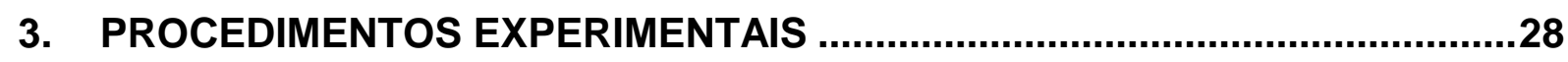

3.1. INTRODUÇÃO

3.2. FABRICAÇÃO DO SISTEMA DE DETECÇÃO DE OXIGÊNIO DISSOLVIDO …................29

3.2.1. Fabricação do sensor de fibra óptica para detecção de oxigênio

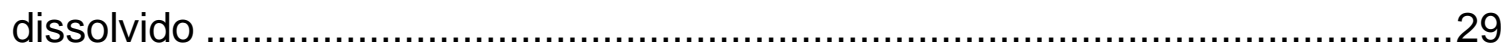

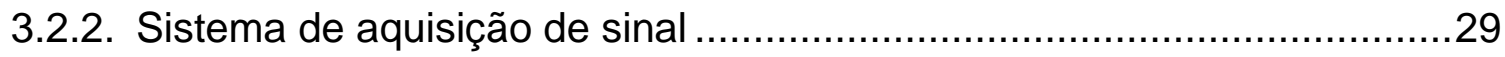

3.3. ARRANJO EXPERIMENTAL DO SISTEMA DE CONTROLE DE OXIGÊNIO DISSOLVIDO ..32

3.4. Sistema Portátil Multiespectral para Monitoramento da TaXa de

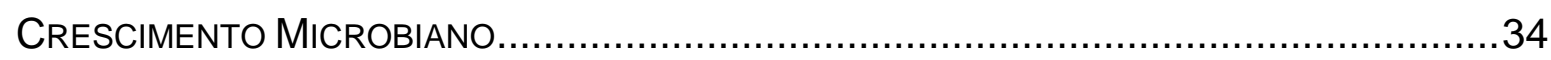

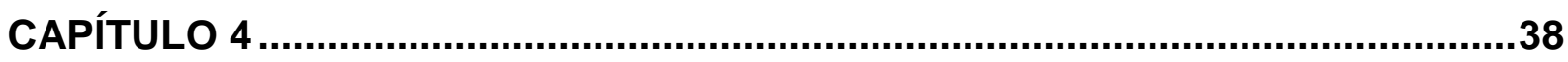

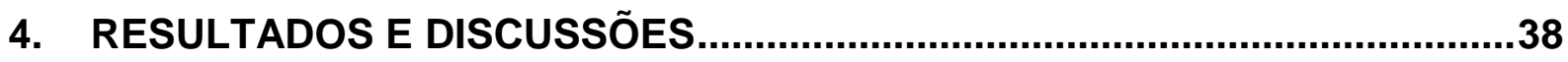

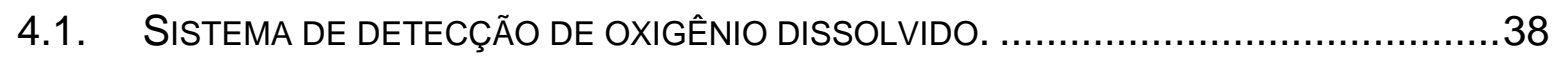

4.2. SISTEMA MULTIESPECTRAL PORTÁTIL PARA MONITORAMENTO DA TAXA DE

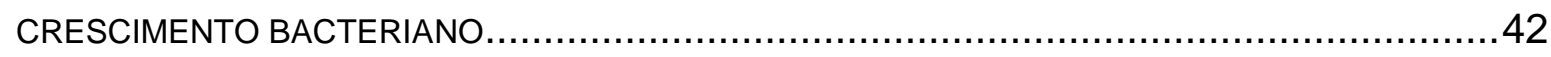

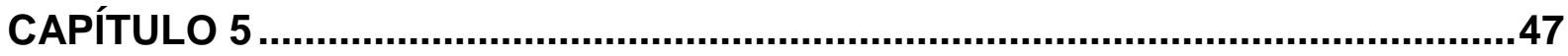




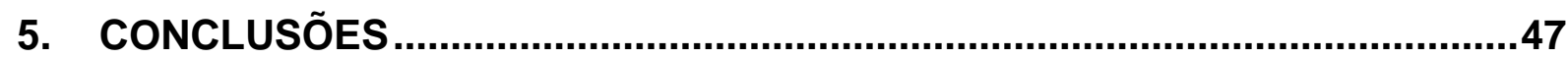

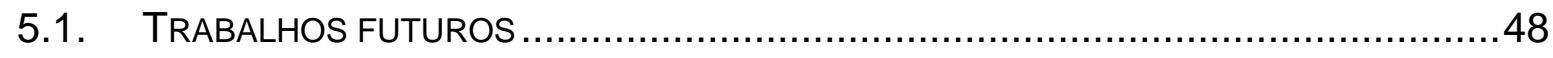

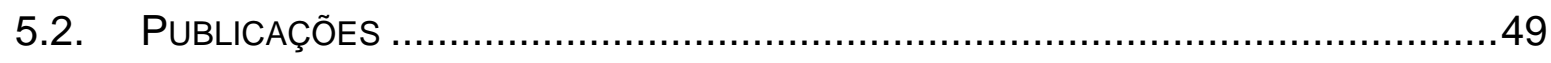

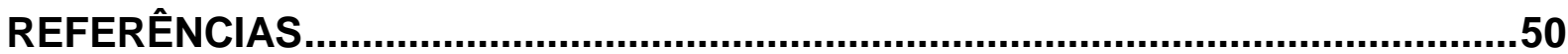




\section{Prefácio}

O trabalho apresenta resultados do desenvolvimento de um sistema de monitoração de meios de cultura em soluções aquosas. Nesse sentido foi desenvolvido um sensor para monitorar a concentração de oxigênio dissolvido em meios aquosos utilizandose fibras ópticas de tal forma que o sistema desenvolvido seja uma sonda que pode ser utilizada em qualquer ambiente aquoso. Em paralelo foi desenvolvido um sistema espectrômetro portátil tipo sonda, este sistema permitiu monitorar o crescimento de bactérias que podem ser aplicadas na remediação ambiental em meios contaminados com íons de cobre. Este trabalho foi desenvolvido em cooperação com o Centro de Capacitação e Pesquisa em Meio Ambiente - CEPEMA-USP, localizado na cidade de Cubatão-SP, onde são desenvolvidas pesquisas de biorremediação em ambientes contaminados por íons metálicos. Os resultados desta dissertação são detalhados sistematicamente em cinco capítulos. No primeiro capítulo são descritos a importância do monitoramento de oxigênio dissolvido em meios aquosos e o estado da arte dos dispositivos aplicados com este propósito assim como a importância da biorremediação e das diferentes técnicas de monitoração destes processos. No capítulo 2 é detalhado os objetivos e justificativas da dissertação de mestrado. No capítulo 3 é detalhado os procedimentos e métodos experimentais utilizados no desenvolvimento dos sistemas de monitoração de oxigênio dissolvido e do espectrômetro portátil. No capítulo 4 são apresentados e discutidos os resultados experimentais obtidos nos sistemas propostos através da obtenção de curvas de calibração da resposta dos sensores. Finalmente, no capítulo 5 são detalhadas as principais conclusões e contribuições da presente dissertação. 


\section{Capítulo 1}

\section{Introdução}

Nos sistemas biológicos, a concentração de oxigênio dissolvido resulta de fundamental importância no processo dinâmico de crescimento e morte de bactérias e outros sistemas biológicos. Nesse sentido, as moléculas de oxigênio são compostos primordiais para manutenção da vida de sistemas biológicos em meio aquático, sendo a quantidade de oxigênio em água um bom indicador para qualidade nos rios, lagos e fontes de água (BHARDWAJ, 2015; O'NEILL, 2015; TURNER et al., 2015). A concentração de oxigênio dissolvido (OD) em meio líquido, além de ser essencial para a vida nesse meio, é um importante parâmetro de aplicações em diversos campos e atividades, como por exemplo, na indústria médica: oxigenoterapia ou em tratamentos nas câmaras hiperbáricas, na indústria de alimentos (BRAGA,2016) - na fabricação de laticínios, sucos e glaciamento de carnes, onde a água acaba incorporando-se ao produto, além da necessidade de se manter a integridade das embalagens e dos próprios tanques utilizados nos processos de fabricação. No monitoramento ambiental torna-se um parâmetro que indica a poluição em meio aquático, compondo índices de qualidade da água, a saber: IVA (índice de qualidade de águas para proteção da vida aquática e de comunidades aquáticas), considerado primordial para a biota; IPMCA (índice de variáveis mínimas para preservação da vida aquática) sendo $O \mathrm{OD}$ agrupado nesse índice como variável essencial (CETESB, 2014). Na área específica de microbiologia, a determinação de oxigênio dissolvido torna-se de extrema importância para obtenção de parâmetros que indicam a dinâmica de crescimento microbiano em meio aquoso. Desta forma, o OD é um elemento que indica a existência de atividade microbiana aeróbica, onde sua presença na solução é condição indispensável para a atividade no meio. Por este motivo, em sistemas de biorremediação, onde são inseridas bactérias aeróbias, controlar e monitorar a presença de OD significa garantir o sucesso do processo. Portanto, é possível correlacionar o crescimento microbiano com a quantidade de oxigênio dissolvido (OD) presente no meio. 
A biorremediação é por definição o uso de microrganismos e suas diversidades metabólicas para reduzir ou eliminar a contaminação por inapropriada disposição de substâncias tóxicas, em resíduos industriais e em lagoas de rejeitos de minérios em processos de mineração (ALHO, 2008; PERPÉTUO,2011; KENSA, 2011; MICHAEL; UNTERMAN, 1993; ADAMS et al.,2015). Uma das grandes vantagens da biorremediação é a possibilidade de usar os microrganismos que já vivem em contato com esses poluentes, e que, portanto, possuem a capacidade e a resistência metabólica para atuar no processo de eliminação desses contaminantes (KUMAR,2011; GAUR et al., 2014). Na maioria dos casos, o meio ambiente em si providencia os microrganismos necessários ao processo, e as pesquisas são responsáveis por aperfeiçoar os resultados obtidos através dos estudos de melhoria e otimização das condições de cultivo celular.

Assim, torna-se necessário o desenvolvimento de tecnologias de baixo custo e altamente adaptativas, com vantagens de se obter dados em tempo real do processo de crescimento microbiano. Em atividades de cultura celular, o monitoramento do processo em tempo real tornaria desnecessária a preparação de amostras toda vez que fosse necessário realizar medidas de concentração bacteriana, facilitando assim, a execução de longos experimentos e na tomada de decisão para conduta de cultivação, por exemplo. A concentração celular (bacteriana) pode ser obtida através da correlação entre medidas de absorbância (densidade celular) e medidas de peso de massa seca (MONOD, 1949).

Os métodos mais amplamente usados para leitura de crescimento bacteriano são baseados na determinação por transmissão ou dispersão de luz (MONOD, 1949; WIDDEL, 2007). Atualmente, o uso de sensores ópticos tem sido difundido largamente para monitoramento de diversas atividades, desde as mais simples até as de maior complexidade. Afim de monitorar a concentração de OD, bem como, o crescimento bacteriano, dispositivos sensores baseados na emissão por fluorescência têm sido usados com sucesso para detecção de gás oxigênio. Esse dispositivo utiliza moléculas corantes fluorescentes incorporadas em matrizes hospedeiras poliméricas, onde o princípio de detecção do oxigênio é baseado no efeito da supressão da fotoluminescência

(WOLFBEIS, 1991; MOHR,1995;

VAUGHAN,1996; MCMURRAY,1994; RAMASAMY,1983; AMAO,2003). Nestes sensores fluorescentes, a detecção do oxigênio depende da permeabilidade da matriz hospedeira, e assim, influenciam na sensibilidade do dispositivo. Por esta razão, muitas matrizes 
hospedeiras têm sido propostas para melhorar a sensibilidade do sensor (WOLFBEIS,1991; MOHR,1995; VAUGHAN,1996; MCMURRAY,1994; RAMASAMY,1983; AMAO,2003).

A detecção de OD em meio aquoso é ainda um desafio para fabricação de dispositivos sensores baseados em fluorescência. Desta forma, vários estudos têm relacionado o uso de fibras ópticas, com a incorporação de moléculas corantes imobilizadas em matriz hospedeira polimérica em suas extremidades (CHENG-SHANE,2010; YANG et al., 2013) ou em superfície afunilada (PULIDO; ESTEBAN, 2010). Todas as propostas de sensores ópticos baseados em fluorescência utilizam um espectrômetro para detecção do sinal fluorescente (CHENG-SHANE, 2010; YANG et al., 2013; PULIDO; ESTEBAN, 2010) tornando dificultosa a utilização deste sensor para medição in-situ, como por exemplo na água de rios e lagos. Neste sentido, a seguir descreveremos o estado da arte utilizados na deteç̧ão de OD e $\mathrm{O}_{2}$.

\subsection{Sensores para detecção de $\mathrm{O}_{2}$ e OD}

Os métodos tradicionais de monitoramento de OD normalmente são baseados em sensores eletroquímicos e denominam-se sensores de Clark. O sensor de Clark (Figura 1) se baseia na aplicação de uma determinada tensão entre dois eletrodos, gerando uma corrente pela redução eletrolítica do OD na solução. Esses eletrodos costumam ser frágeis e consomem oxigênio do meio (BRAGA, 2016).

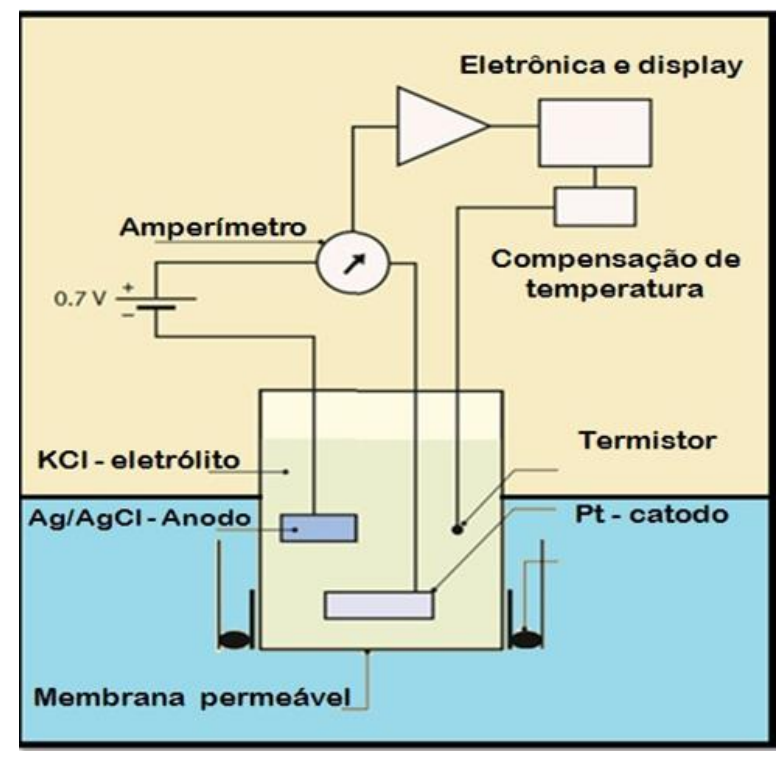

Figura 1 - Representação esquemática do Eletrodo de Clark. 
Recentemente, uma variedade de dispositivos sensores baseados em supressão da fotoluminescência, com o uso de moléculas corantes orgânicas como parte sensível do sensor, foi desenvolvida para medidas de oxigênio e oxigênio dissolvido devido à alta sensibilidade, zero consumo de oxigênio e fácil operação (medidas on-line, em tempo real).

Uma série de fluoróforos foram explorados como sondas de oxigênio luminescentes com este propósito, entre eles, os hidrocarbonetos aromáticos policíclicos (PAHs) (LEE; WERNER; SEITZ, 1987), como o pireno, ácido pirenebutírico, quinolina, fenantreno e complexos de metal de transição como rutênio, ósmio e rênio são mais frequentemente apontados como alternativas para essas aplicações (LEE; OKURA, 1998). A grande maioria dos corantes orgânicos usados para o desenvolvimento de sensores ópticos de oxigênio dissolvido apresentam a desvantagem de ter a região de excitação próxima a região de emissão, ou seja, apresentam um pequeno deslocamento de Stokes, exigindo assim uma instrumentação óptica mais complicada e dispendiosa para a separação da luz de excitação do sinal de luminescência. Portanto, a escolha do corante com um deslocamento de Stokes significativo é um fator importante para determinar as propriedades dos sensores (LEE; OKURA, 1998). As metaloporfirinas mostraram-se bons candidatos para sensores ópticos de detecção de oxigênio devido sua alta sensibilidade (AMAO, 2003). As metaloporfirinas citadas em estado excitado possuem forte interação spin-orbital entre o elétron do sub-nível "d" do metal e o orbital anti-ligante $\mathrm{p}^{*}$ dos anéis da porfirina promovendo um decaimento para um estado excitado tripleto. Assim a maior emissão vem do estado tripleto de menor energia, o qual pode ser suprimido pelo oxigênio, razão pela qual esses complexos apresentam excelente sensibilidade ao $\mathrm{O}_{2}$ e OD. (BRAGA, 2016)

Os complexos de platina (Pt) e paládio (Pd) (Figura 2) são os compostos mais conhecidos entre as metaloporfirinas que apresentam elevada sensibilidade para a detecção de oxigênio dissolvido (AMAO, 2003). 
a)

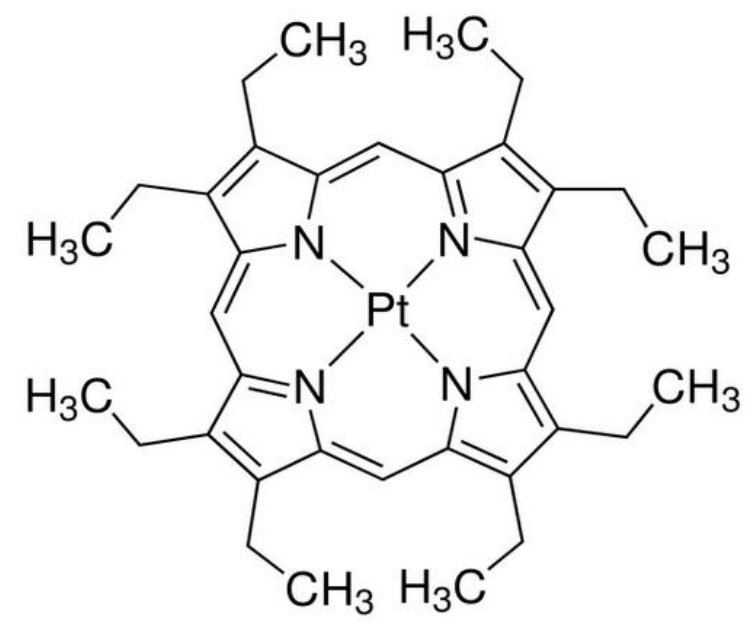

b)

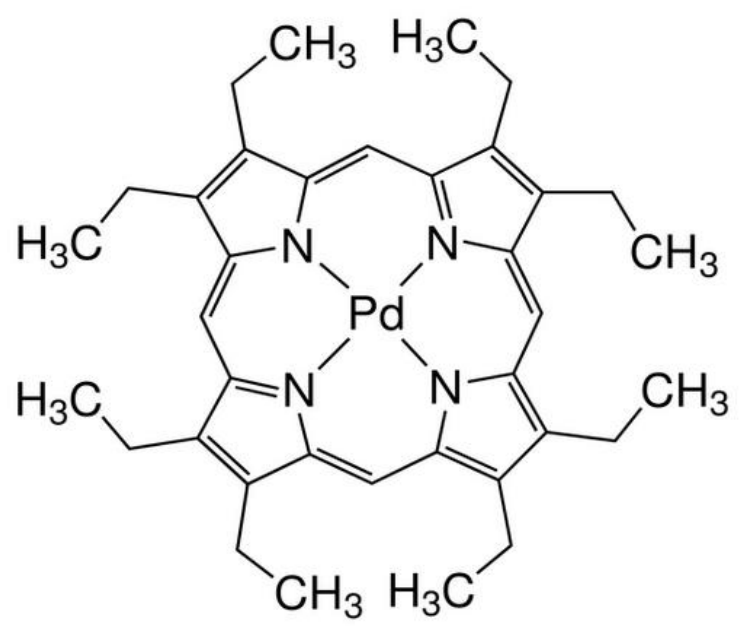

Figura 2 -Complexos de Platina e Paládio (a) Octaetilporfirina de Platina (PtOEP) (b) Octaetilporfirina de Paládio (PdOEP)

A octaetilporfirina de platina (PtOEP) é um composto que se destaca para funcionalização de sensores ópticos de oxigênio dissolvido devido suas bandas de absorção estarem na região de 480-645nm, o que facilita a utilização de diodos emissores de luz (LED's) para excitação do sensor. O deslocamento de Stokes é da ordem de $100 \mathrm{~nm}$, o que evita problemas de reabsorção. Além disso, seu longo tempo de vida de estado excitado é uma das grandes razões para ser utilizado como sensor óptico. Assim, a porfirina de platina, em especial a PtOEP foi escolhida para obtenção dos filmes finos do dispositivo sensor de $O D$ e do sistema multiespectral para monitoramento bacteriano por apresentar sensibilidade às moléculas de oxigênio (LEE; PARK, 2017). Como já abordado, o princípio por trás do funcionamento deste sensor é a redução da intensidade da fotoluminescência como consequência da presença de oxigênio dissolvido no meio. A maioria dos trabalhos discutem seus resultados em termos de análise Stern - Volmer que relaciona a supressão da emissão fotoluminescente e a concentração de OD.

$$
\frac{\mathrm{I}_{0}}{\mathrm{I}}=1+\operatorname{Ksv}\left[\mathrm{O}_{2}\right]
$$

Onde: $I_{0}$ e I são as intensidades de fotoluminescência na ausência e na presença de oxigênio, respectivamente, e Ksv é a constante de Stern-Volmer que tem como unidade a inversa da concentração do analito, que neste caso corresponde a concentração de oxigênio representado por $\left[\mathrm{O}_{2}\right.$ ]. (LEE; OKURA, 1998). 
A determinação do valor da constante de Stern - Volmer (Ksv) tem relação com a quantificação da sensibilidade do sensor, uma vez que quanto maior o valor de Ksv maior será a sensibilidade do sensor fotoluminescente.

Em algumas atividades onde possam existir alto índice de inflamabilidade, em decorrência do manejo de diversos produtos químicos, principalmente na indústria química, quando em alguns casos, possíveis gerações de qualquer sinal elétrico podem ocasionar explosões, o uso de tecnologia de fibras ópticas para 0 desenvolvimento de sensores de $\mathrm{O}_{2} \mathrm{O}$ OD tem se mostrado satisfatório (ELOSUA et al., 2014). Assim, sensores de oxigênio e OD baseados em fibra óptica se apresentam como uma alternativa para esse tipo de monitoramento.

Em YEAH et al., 2006 é reportado o uso de sensores de oxigênio baseados em fibras ópticas, tendo uma de suas pontas funcionalizadas com dois tipos de revestimento de complexos de platina (Pt), a octaetilporfirina de platina (PtOEP) e a tetra (pentafluorfenil) porfirina de platina (PtTFPP), imobilizados em matrizes de sol-gel. O sensor baseado na fibra óptica é constituído em uma fibra multimodo com bifurcação, sendo a detecção do sinal fotoluminescente realizada com espectrofotômetro de bancada, tal sistema de bancada não possibilita a aplicação em medições in-situ, como rios e lagos. (YEH et al.,2006).

Como mencionado anteriormente, um dos sistemas desenvolvidos neste trabalho é destinado ao monitoramento da taxa de crescimento microbiano, assim sendo, apresentaremos revisão bibliográfica dos métodos convencionalmente utilizados para análise do comportamento do crescimento microbiano.

\subsection{Métodos para quantificação de crescimento microbiano}

Existem vários métodos para estimar a massa ou aumento de quantidade bacteriana, os principais serão discutidos a seguir. 


\subsubsection{Contagem de células viáveis}

Este método permite identificar as células viáveis, que por definição são as células capazes de dividir-se e aumentar o tamanho da colônia. O método consiste em diluir a amostra original numa solução apropriada para o meio de cultura, na sequência, a incubação deve ser monitorada para garantir que as condições necessárias (como temperatura, por exemplo) para viabilizar o crescimento das colônias estão sendo mantidas. Após a incubação, as colônias podem ser contadas desde que se conheça o resultado de cada diluição. O número de células é expresso em unidades formadoras de colônia (UFC), pois em inúmeras vezes não é apenas uma célula que gera uma colônia, mas sim um conjunto de células (bactérias). A Figura 3 mostra o método de diluição e contagem de células viáveis (MANDIGAN et al., 2016).

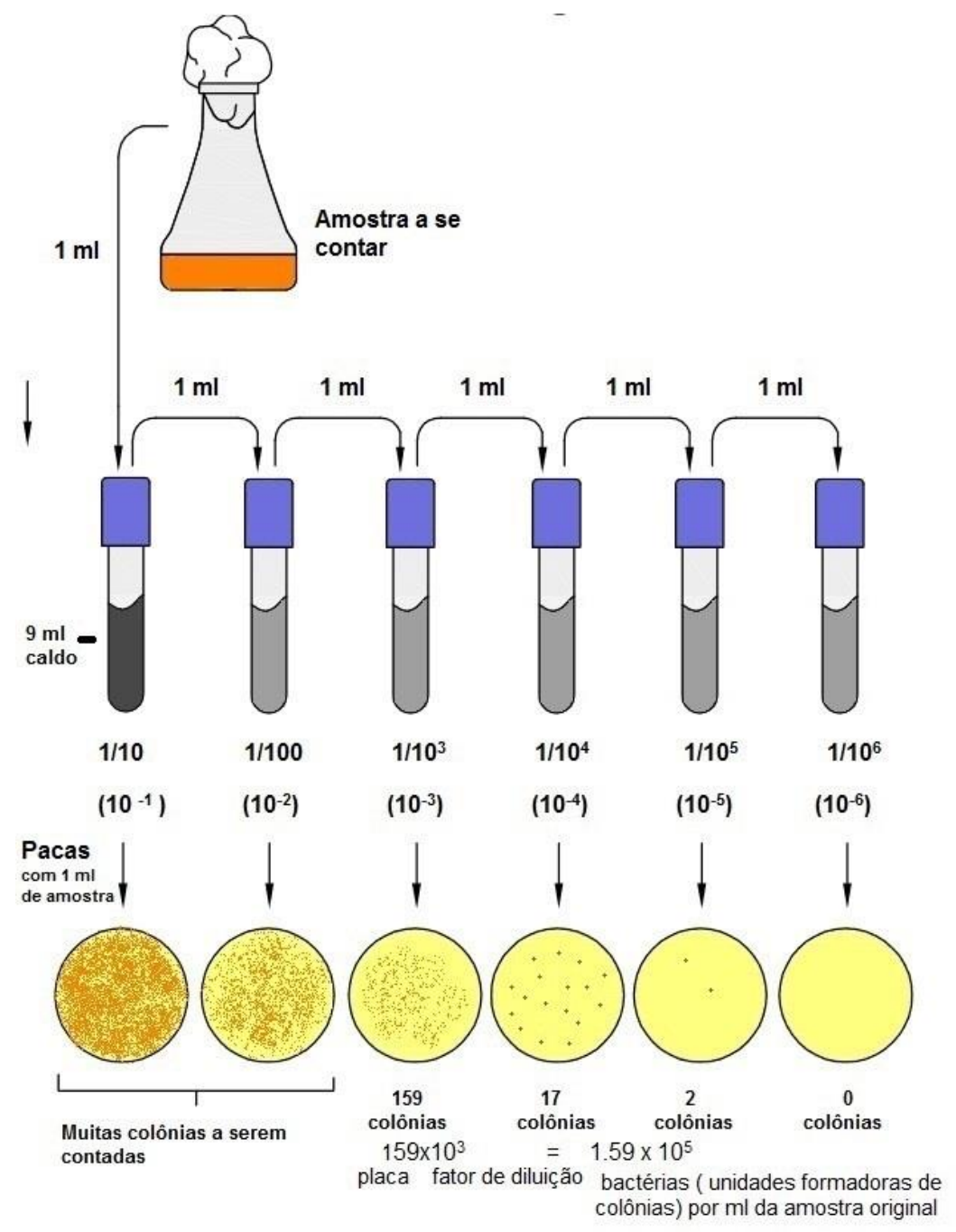

Figura 3- Contagem de células viáveis (MANDIGAN et al., 2016). 
O método é vantajoso no sentido de se contar apenas as células viáveis, ativas, porém, a quantidade de material utilizado, principalmente, a vidraria envolvida na diluição torna o processo trabalhoso e com longa duração. Há de se mencionar também que a menor falha ao manusear qualquer quantidade da diluição acarretará em erro na contagem final do número de células.

\subsubsection{Método espectrofotométrico}

Os componentes celulares aumentam proporcionalmente o número de células quando na fase de crescimento microbiano denominada fase exponencial, e um desses componentes é a própria massa celular. As células dispersam luz, e um método rápido e bastante útil para estimar a massa celular é a turbidez. Uma suspensão celular (bactéria) exibe aspecto turvo quando as células dispersam a luz que atravessa a suspensão. Quanto maior o número de células presentes, maior a quantidade de luz dispersa e, consequentemente, mais turva a suspensão. Uma vez que a massa celular é proporcional ao número de células, a turbidez pode ser utilizada para estimar o seu número (MANDIGAN et al., 2016).

\subsubsection{Densidade óptica (DO)}

A turbidez é a medida com o auxílio de um espectrofotômetro, que promove a passagem de luz através de uma suspensão celular, detectando a quantidade de luz emergente, e não dispersa (ALTERTHUM, 2008). Na Figura 4(a) o espectrofotômetro emprega um prisma ou grade de difração para gerar uma luz incidente de comprimento de onda específico. Os comprimentos de onda normalmente utilizados para medir turbidez bacteriana incluem $480 \mathrm{~nm}$ (azul), $540 \mathrm{~nm}$ (verde), $600 \mathrm{~nm}$ (laranja) e $660 \mathrm{~nm}$ (vermelho), tendo como unidade de medida correspondente a densidade óptica (DO), sendo especificada no comprimento de onda utilizado, como por exemplo DO600, para medidas de densidade óptica em cumprimentos de $600 \mathrm{~nm}$. No caso de organismos unicelulares, a densidade óptica é proporcional, ao número de células (bactérias). (ALTERTHUM, 2008) 
As leituras de turbidez podem, portanto, ser utilizadas como um substituto dos métodos de contagem do total de células ou de células viáveis, contudo, antes desse procedimento ser realizado, uma curva padrão deve ser previamente construída, relacionando o número de células (contagem microscópica ou de células viáveis), peso seco ou teor proteico à turbidez. Como pode ser observada nesse tipo de gráfico, a proporcionalidade é mantida dentro de certos limites Figura 4(c).

a)

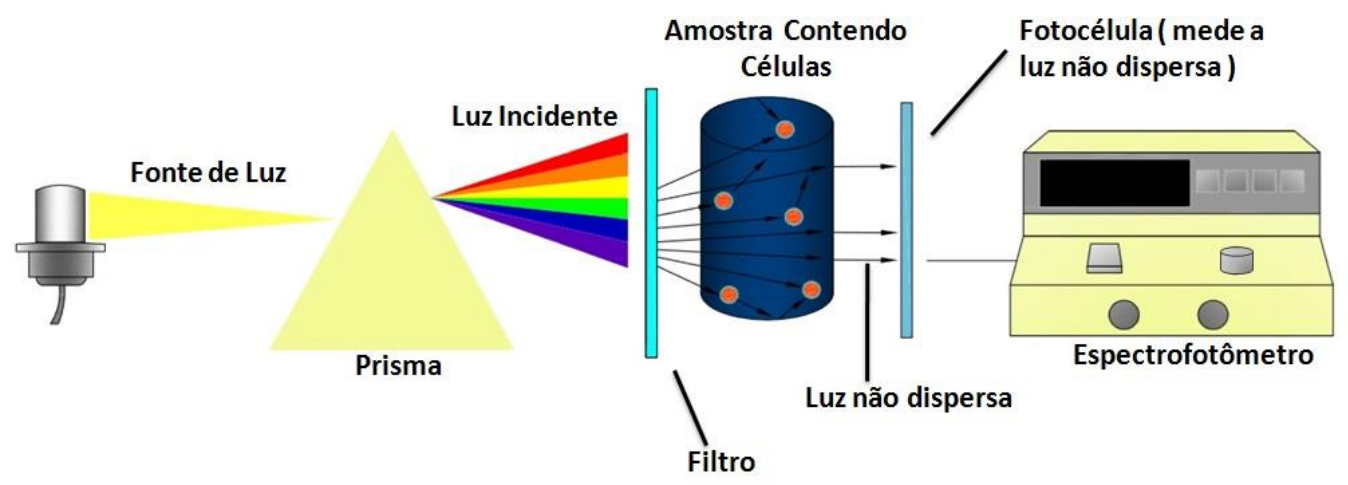

b)

c)
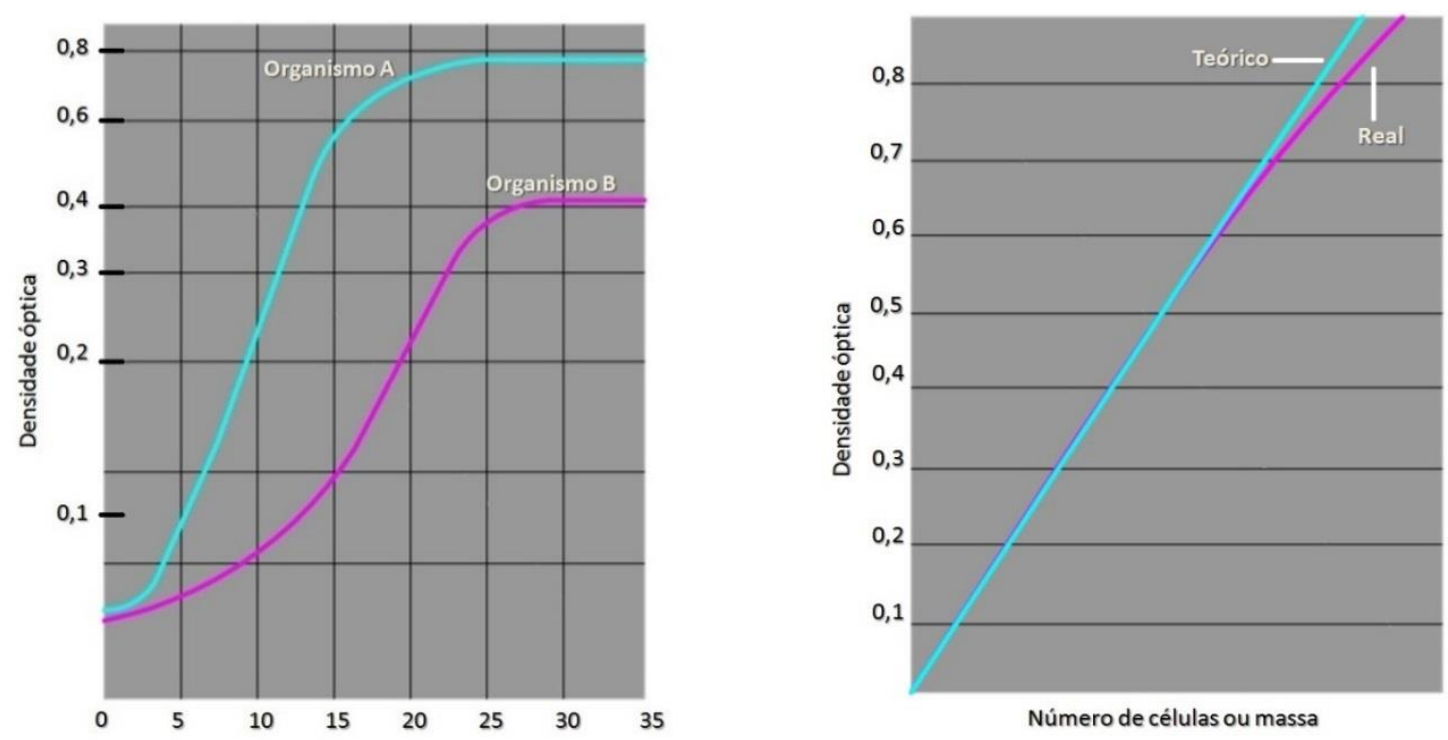

Figura 4- a) turbidez medida no espectrofotômetro. b) curva de crescimento de dois microorganismos, com diferentes taxas de crescimento. c) relação número de células ou peso seco e as medidas de turbidez (ALTERTHUM, 2008) 
O crescimento bacteriano é um somatório de processos metabólicos progressivos, que geralmente conduzem a reprodução. A idade da bactéria é considerada como espaço de tempo entre uma fissão em que a originou e a divisão que a duplicará. Quando uma bactéria é cultivada em meio de cultura líquido e incubada em temperatura adequada tendo também os nutrientes necessários para sua divisão celular é possível que seu crescimento produza uma curva característica (Figura 5) (ALTERTHUM, 2008). Esta curva pode ser definida como curva de crescimento sendo dividida em quatro fases:

a) fase "lag" ou de latência é considerada uma fase de adaptação da bactéria, onde não ocorre crescimento da população, porém há um aumento de massa, apesar de estarem recebendo os nutrientes necessários.

b) fase exponencial onde se inicia a divisão, as bactérias já acostumadas com o meio e após a absorção de todos os nutrientes suficientes para duplicar seus constituintes entram em divisão binária e ocorre o aumento da população em velocidade máxima, a medida que o número de bactérias aumenta é óbvio que a quantidade de nutrientes começa a ficar cada vez menor.

c) fase estacionária onde o metabolismo das bactérias começa a ficar reduzido em virtude da redução de nutrientes, nessa fase poucas bactérias conseguirão se alimentar e entrar em divisão; ao mesmo tempo algumas bactérias começam a perecer por não ter acesso aos nutrientes no meio, nessa fase praticamente 0 nascimento de novas bactérias é igual a morte de bactérias permanecendo o número constante de bactérias. Nesta fase existe também o acúmulo de substâncias tóxicas, os metabólitos como as bactérias eliminam o lixo metabólico no próprio meio, em um dado momento começa a afetar o crescimento microbiano cada vez mais.

d) fase de declínio ou morte onde as bactérias já consumiram os nutrientes (caldo nutritivo) do meio e com a produção de lixo metabólico cada vez maior ocorre a morte das bactérias e extinção da população no meio de cultura. Todo este processo envolvendo as quatro fases é representado na curva de crescimento microbiano onde no eixo vertical é representado o número de indivíduos e no eixo horizontal o tempo (Figura 5). 


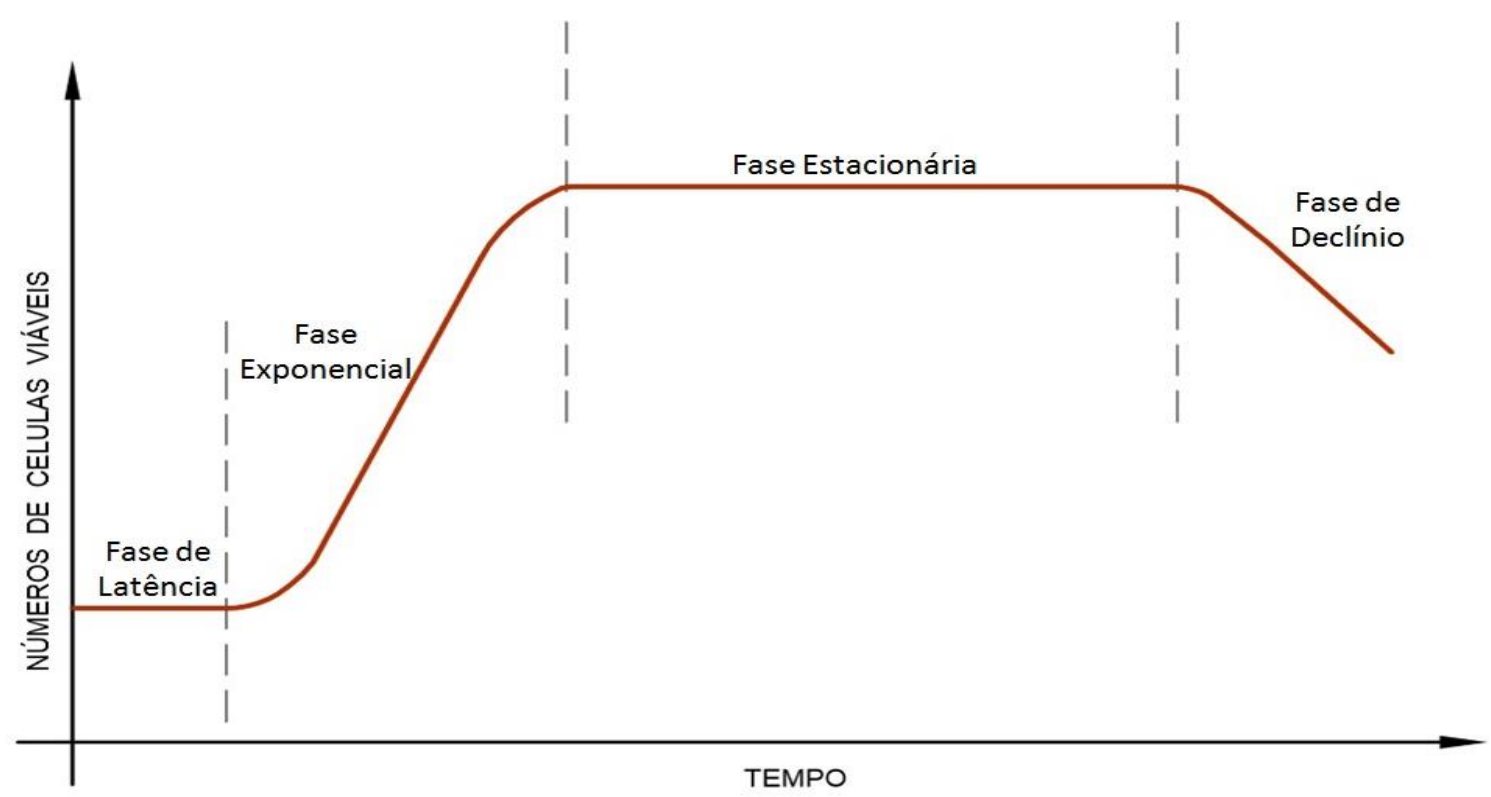

Figura 5- Gráfico representando a curva de crescimento microbiano. (ALTERTHUM, 2008)

$\mathrm{Na}$ fase exponencial, como dito anteriormente, a reprodução ocorre em velocidade máxima e constante por fissão binária (divisão celular), a geração de bactérias ocorre na forma de progressão geométrica 1:2:4:8:16:32. Sendo escrito de outra forma podese representar a divisão celular (razão 2) definido a seguinte Equação 2. (ALTERTHUM, 2008)

$$
\log \mathrm{N}=\log \mathrm{No}+\operatorname{nlog} 2
$$

Onde: No é o número inicial de bactérias; $\mathbf{n}$ é o número de gerações ocorridas após o tempo (t) e $\mathbf{N}$ é o número de bactérias após determinado tempo. Nota-se que essa é a equação de uma reta, onde No é a ordenada na origem e $\mathbf{n}$ no declive ou coeficiente angular. A partir da Equação 2 é possível calcular o número de gerações no meio de cultura através da Equação 3.

$$
\mathrm{n}=\frac{\log \left(\frac{\mathrm{N}}{\mathrm{No}_{\mathrm{O}}}\right)}{\log 2}
$$

Neste trabalho foram propostos e desenvolvidos dois sistemas portáteis, sendo um para o monitoramento de OD em meio aquoso e outro sistema para monitoramento 
da taxa de crescimento bacteriano, baseado na mudança da absorção óptica do meio de cultura. O sistema é composto por uma matriz de fotodiodos multiespectral e um diodo emissor de luz (LED) como fonte de excitação. No caso do sistema de detecção de OD, em adição foi projetado e fabricado um sistema de sensoriamento baseado na fluorescência da molécula de octaetilporfirina de platina depositada em um dos extremos da fibra óptica multimodo. Este sistema portátil pode ser utilizado em medição in-situ em qualquer ambiente aquático para detecção de OD e monitoramento da dinâmica de crescimento bacteriano. 


\section{Capítulo 2}

\section{OBJETIVOS}

O presente trabalho teve como objetivo o desenvolvimento de dois sistemas: um para monitoramento de oxigênio dissolvido a partir do sensoriamento óptico baseado em fibras ópticas para o monitoramento em tempo real em meios aquosos e outro sistema desenvolvido para monitoramento da taxa de crescimento microbiano.

Para sensor de fibra óptica baseado em fluorescência para OD foi utilizado um circuito integrado de fotodetectores para detecção da fluorescência com saída RGB. Uma das pontas da fibra óptica foi funcionalizada para a detecção de OD pela deposição de um filme fino de PVC, dopado com moléculas corantes de PtOEP, como parte sensível do sensor.

O sistema multiespectral portátil proposto para monitoramento do crescimento microbiano foi baseado em fotodetector optoeletrônico e integrado a hardware embarcado com aquisição, controle e processamento de sinais, baseado em tecnologia FPGA, tendo como ambiente de programação, software baseado em instrumentação virtual $\left(\mathrm{NI}\right.$ LabView $\left.{ }^{\circledR}\right)$ para o monitoramento em tempo real da atividade microbiana no meio de cultura. Para excitação luminosa foram utilizados diodos emissores de luz (LED) com comprimento de onda de $600 \mathrm{~nm}$. 


\subsection{Justificativas}

Um indicador importante da qualidade da água é a quantidade de oxigênio dissolvido (OD), sendo este um parâmetro para determinar a presença de matéria orgânica (MO) na água e possíveis agentes poluidores. Quando existe matéria orgânica, no meio há uma grande possibilidade de ocorrência de crescimento de bactérias aeróbias. Desta forma, torna-se possível correlacionar a quantidade de bactérias que irão se alimentar da MO contida no meio, com a diminuição de oxigênio dissolvido disponível no ambiente.

Neste sentido muitos trabalhos vêm sendo desenvolvidos utilizando-se o crescimento de microorganismos (bactérias) como métodos para biorremediação, onde plantas e microorganismos são utilizados para remover ou reduzir poluentes do meio ambiente. A biorremediação tem várias aplicações incluindo a descontaminação de águas subterrâneas, solo, lodo e efluentes, seja pela contaminação por compostos orgânicos ou por íons metálicos.

Várias técnicas são empregadas para quantificar o crescimento microbiano. Entretanto, os experimentos normalmente são longos e laboriosos, exigindo do pesquisador horas de concentração para realização bem-sucedida do processo.

A necessidade de se monitorar em tempo real a taxa de crescimento bacteriano e simultaneamente a quantidade de oxigênio dissolvido no meio é a grande motivação para integrar este sistema e aplicá-lo no monitoramento em tempo real do crescimento de microorganismos. Isto permitirá identificar o microorganismo que melhor se destaca em poder de biorremediação sobre o processo de descontaminação.

Neste contexto, o desenvolvimento de sistemas de sensoriamento óptico baseado em fibras ópticas para monitoramento da taxa de crescimento microbiano em tempo real e monitoramento das concentrações de oxigênio dissolvido (OD) em meios de cultura e ambientes aquosos torna-se uma alternativa atraente para a otimização do monitoramento de processos de biorremediação de forma eficaz, rápida e in-situ, dispensando o uso de grandes equipamentos usados em laboratório. 


\section{Capítulo 3}

\section{Procedimentos Experimentais}

\subsection{Introdução}

A seguir são detalhados os procedimentos experimentais propostos e implementados para a fabricação do sensor de fibra óptica para detecção de oxigênio dissolvido e a fabricação do espectrômetro portátil utilizado no monitoramento de crescimento de bactérias. Os procedimentos de fabricação propostos neste trabalho representam as principais contribuições da dissertação de mestrado, já que, por exemplo, na fabricação do sensor de oxigênio dissolvido tipo sonda foi proposto a funcionalização da fibra óptica com moléculas corantes sensíveis às moléculas de oxigênio. Adicionalmente, neste sistema foi proposto a implementação de um detector multiespectral integrado tornando o sistema portátil e integrado numa placa de aquisição de dados que permite sua comunicação com computadores externos via USB. No caso da proposta do espectrômetro portátil, podemos mencionar que a contribuição está atrelada à integração do sistema de excitação e detecção via um diodo LED de emissão de luz branca e um detector multiespectral integrado junto à placa de aquisição. Os sistemas propostos são sistemas portáteis e "plug and play" com servidores computacionais via USB. Adicionalmente no presente trabalho foi proposto um sistema de controle da concentração de oxigênio dissolvido controlado via computador num instrumento virtual utilizando a mesma placa de aquisição dos sistemas anteriormente mencionados. A seguir estão descritos detalhadamente os procedimentos seguidos para fabricar os sistemas acima explicados. 


\subsection{Fabricação do sistema de detecção de oxigênio dissolvido}

Este sistema está constituído por dois subsistemas, o subsistema sensor baseado em fibra óptica e o subsistema de detecção constituído com um detector multiespectral.

\subsubsection{Fabricação do sensor de fibra óptica para detecção de oxigênio dissolvido}

O sensor foi fabricado utilizando fibra óptica multimodo GH4001- ESKATM baseada em resina polimetilmetacrilato com diâmetro de núcleo de 0,980 mm e índice de refração de 1.49. Estas fibras ópticas são fabricadas por Mitsubishi Ryon Co. Ltda. A parte sensível do sensor foi desenvolvida utilizando um filme fino de Poli (cloreto de vinila) (PVC) como matriz hospedeira onde moléculas de octaetilporfirina de platina foram depositadas. Com esta finalidade foi preparada uma mistura de 2,2 $\mathrm{mg}$ de PtOEP e $100 \mathrm{mg}$ de PVC diluída em 1,5 ml de solvente de tetrahidrofurano (THF) em seguida, foi adicionado à solução $0,218 \mathrm{ml}$ de Bis (2-ethylhexyl) sebacate (DOS). Afim de se obter uma mistura homogênea, a solução foi agitada mecanicamente em banho ultrassônico por 30 minutos. Para deposição do filme ativo sensível, uma das extremidades da fibra óptica foi imersa na solução preparada e para garantir a secagem total do filme, a ponta da fibra óptica foi mantida em temperatura constante de $60^{\circ} \mathrm{C}$, durante 30 minutos. O filme de PtOEP-PVC encobriu completamente a área da superfície do núcleo da fibra óptica. (BRAGA et al.,2014)

\subsubsection{Sistema de aquisição de sinal}

A intensidade da emissão fluorescente das moléculas de PtOEP foram medidas através de um sistema fotodetector de circuito integrado (Figura 6). Neste dispositivo, a região sensível é composta por 64 fotodiodos que formam uma matriz $8 \times 8$, a matriz de diodos é interconectada a um circuito eletrônico que converte o sinal de corrente em frequência, isto é, o sinal de saída é medido em valores de frequência. O sistema 
é encapsulado em circuito integrado monolítico CMOS tipo TCS3200 fabricado por AMS Company. A matriz $8 \times 8$ de fotodiodos é dividida em 4 grupos sendo cada um deles com sub-matrizes $4 \times 4$ conectadas em paralelo por leiaute interdigitado sendo, três grupos de sub-matrizes com filtros RGB, respectivamente (16 filtros vermelhos, 16 filtros verdes e 16 filtros azuis) e um grupo sem filtro (16 fotodiodos). O sistema fotodetector possui apenas uma saída, então, o sinal de saída correspondente para cada grupo de fotodiodos com mesmo filtro é selecionado através da combinação binária de duas entradas digitais do circuito integrado S2 e S3 (Tabela 2). O sinal de saída é uma onda quadrada (com ciclo de trabalho de 50\%)de tal forma que a frequência é diretamente proporcional a intensidade da luz incidente na área de superfície ativa do sistema fotodetector. Em adição, é possível selecionar a região de frequência do sinal de saída através da combinação binária entre os pinos S0 e S1 (Tabela 1).

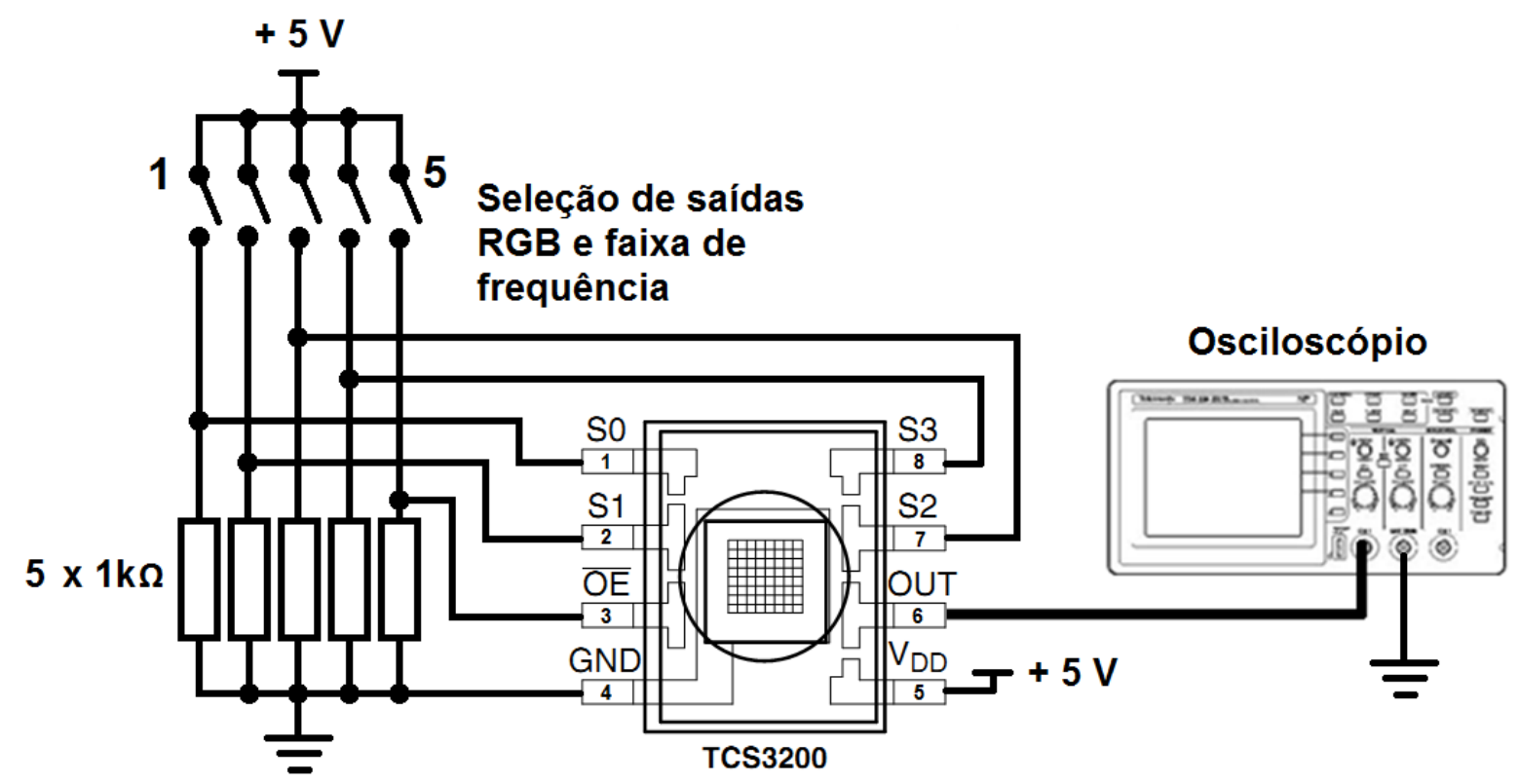

Figura 6 -Diagrama esquemático do arranjo experimental para caracterização do fotodetector TCS3200 como sistema de medida de fotoluminescência. 
Tabela 1 -Opções selecionáveis para fotodiodos: Seleção da região de frequência do sinal de saída

\begin{tabular}{lll}
\hline S0 & S1 & Escala de frequência de saída (fo) \\
\hline L & L & Desligado \\
L & H & $2 \%$ \\
H & L & $20 \%$ \\
H & H & $100 \%$ \\
\hline
\end{tabular}

Tabela 2 -Seleção da frequência de saída: combinação binária de duas entradas digitais do circuito integrado S2 e S3

\begin{tabular}{lll}
\hline S2 & S3 & Escala de frequência de saída (fo) \\
\hline L & L & Vermelho \\
L & H & Azul \\
H & L & Sem filtro \\
H & H & Verde \\
\hline
\end{tabular}

As moléculas sensíveis (PtOEP) foram excitadas com diodo LED-UV $(1,3 \mathrm{~mW}, \lambda=$ $377 \mathrm{~nm}$ ) fabricado por Lumex Company. A intensidade da luz de emissão vinda do LED foi mantida constante durante o processo de medição devido a aplicação de uma polarização constante $V_{\text {dc }}$ igual a 3,6 Volts. A Figura 7 mostra o diagrama esquemático da fonte de excitação que atua em uma das extremidades da fibra óptica, tendo na extremidade oposta o sensor RGB posicionado para medida da intensidade de emissão fotoluminescente das moléculas de PtOEP, sendo a região sensível do sensor. Nesta configuração o sensor poderia ser utilizado como sensor tipo sonda. 


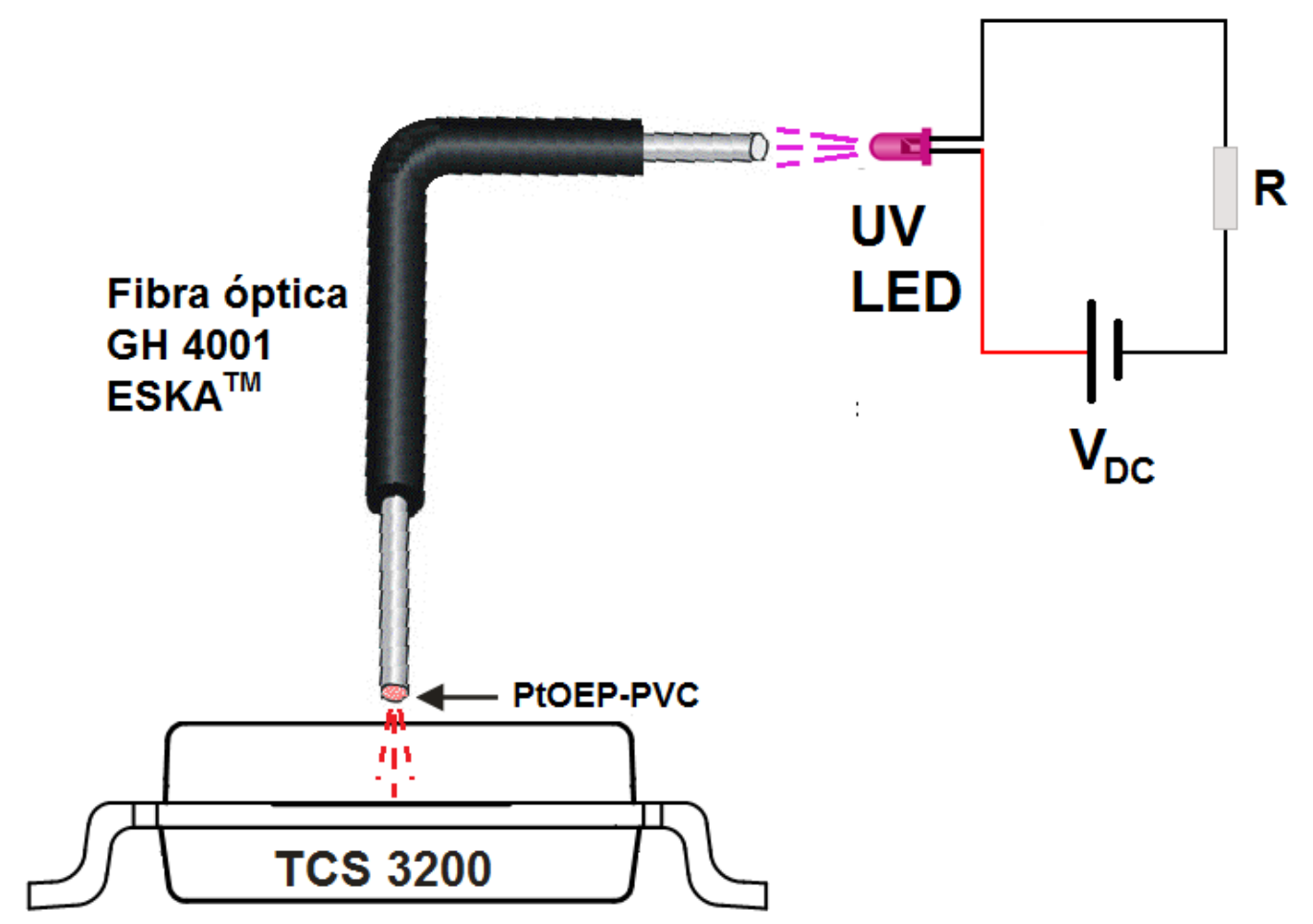

Figura 7 - Diagrama esquemático do arranjo experimental de medida do OD.

\subsection{Arranjo experimental do sistema de controle de oxigênio dissolvido}

Para obtenção da curva de calibração de resposta do sensor de fibra óptica foi projetado um sistema experimental de maneira similar ao desenvolvido por Braga (2016) que permite controlar a concentração de oxigênio em meio aquoso. Comeste objetivo, $200 \mathrm{ml}$ de água deionizada foi colocada em frasco cônico (Kitasato) de 250 $\mathrm{ml}$ e injetado uma mistura de gases $\mathrm{O}_{2}$ e $\mathrm{N}_{2}$ utilizando um borbulhador metálico para reduzir a formação de bolhas na água. Este procedimento facilita o processo de oxigenação e desoxigenação da água reduzindo ao máximo o tempo morto durante o processo de medição. $O$ bombeamento da água deionizada com oxigênio dissolvido foi realizado por uma bomba peristáltica da marca Milan modelo 204. A Figura 8 mostra o diagrama esquemático do sistema utilizado para controlar a concentração de OD no meio aquoso utilizado no processo de calibração. 


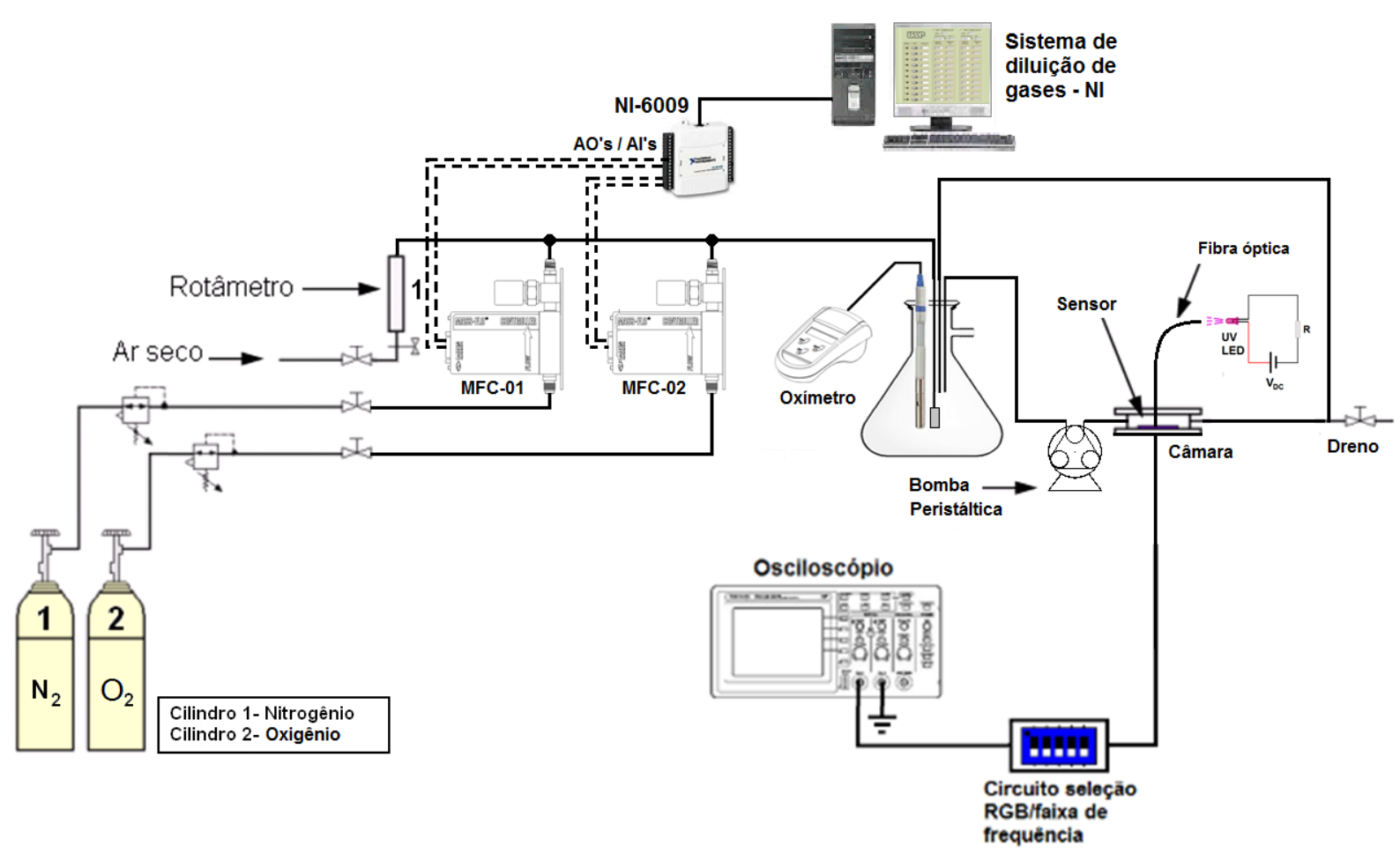

Figura 8 - Diagrama esquemático do sistema utilizado para controlar a concentração de OD em água deionizada.

A Figura 9 apresenta o diagrama esquemático utilizado para obtenção da resposta dinâmica do sensor que foi verificada utilizando o sistema desenvolvido por Braga (2016) onde ao sistema para controle de OD (Figura 8) é adicionado outro frasco cônico e uma válvula de controle direcional de 5/2 vias com acionamento duplo solenoide. Esta configuração permitiu a transição rápida entre o frasco com água sem a presença de OD Kitasato $\mathrm{KT}-01(0 \mathrm{mg} / \mathrm{l})$ para o frasco com água saturada de $\mathrm{OD}$ Kitasato KT-02 (20mg/l). Este controle foi realizado através da ativação das válvulas solenoides S1 e S2 que são controladas por aplicativo por duas saídas digitais localizadas na placa de aquisição. Com a finalidade de se evitar qualquer variação interna nas concentrações de OD para cada frasco (KT-01 e KT- 02), foi instalada uma válvula de controle direcional de 3/2 vias com acionamento por solenóide e retorno por mola na saída da câmara do sensor. Neste processo de medição a válvula S3 é acionada sempre 2 segundos após S1 ou S2 ser acionada, deste modo, evita-se que qualquer líquido remanescente permaneça na linha da câmara, retornando quase que totalmente para o frasco correspondente permitindo obter a condição anterior na câmara do sensor, antes de novos ensaios. As vazões nas bombas peristálticas B01 e B02 foram iguais e constantes em $100 \mathrm{~mL} / \mathrm{min}$ durante a realização dos testes. 


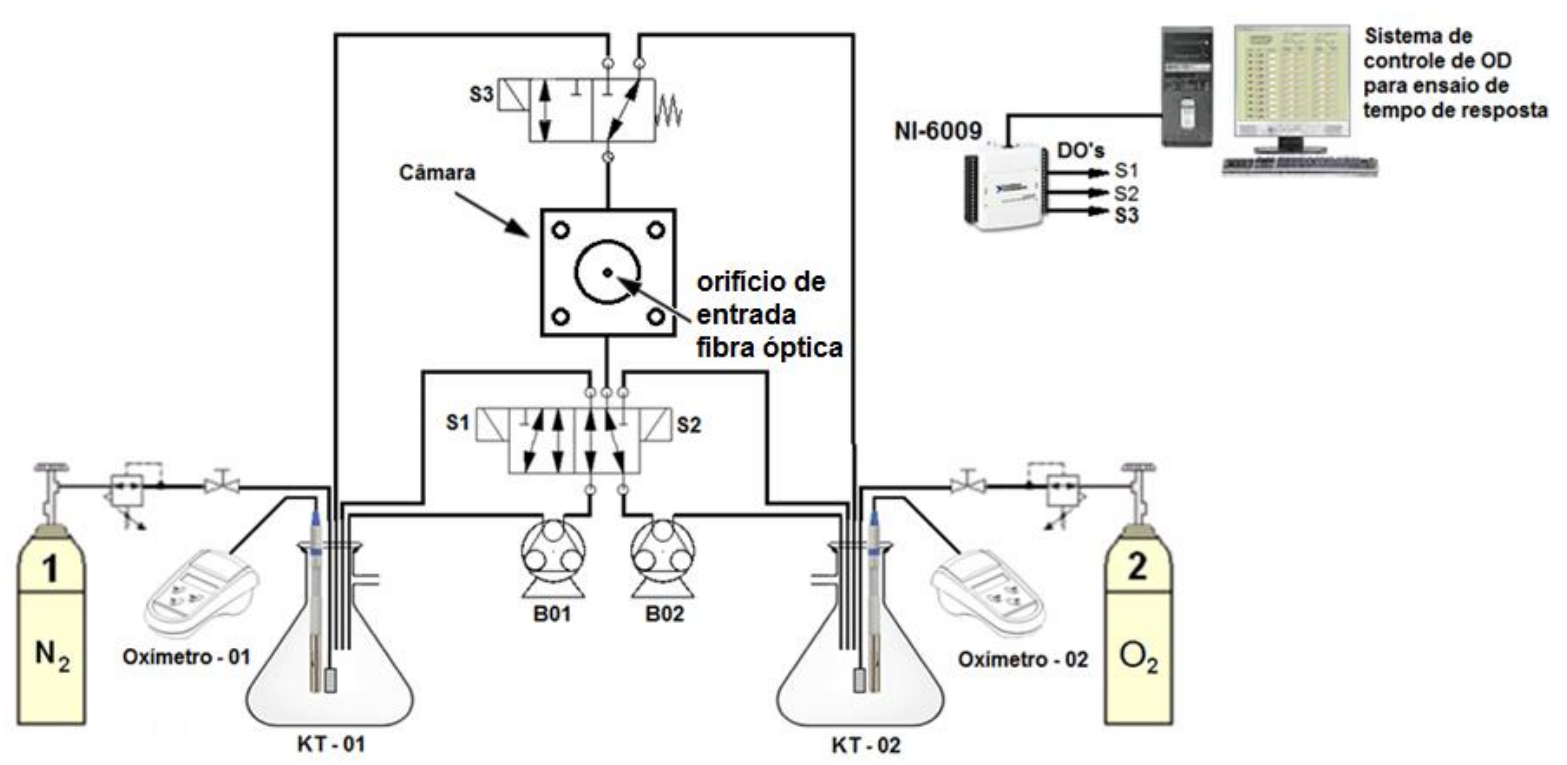

Figura 9 - Diagrama esquemático do sistema para controle de OD utilizado para análise da resposta dinâmica do sensor

\subsection{Sistema Portátil Multiespectral para Monitoramento da Taxa de Crescimento Microbiano}

O sistema portátil é baseado em dispositivos fotodetectores optoeletrônicos encapsulados em mesmo invólucro, formando um conjunto de 18 fotodiodos (matrizes 3x6) em circuito integrado tipo MMCS6CS, fabricado por MAZeT Company (BRAGA, 2015, 2016, 2017). Neste dispositivo há três grupos de seis fotodiodos distribuídos simetricamente em estrutura circular de diâmetro igual a $2 \mathrm{~mm}$. Em cada fotodiodo existe um filtro dielétrico espectral que seleciona o comprimento de onda específico a ser detectado. A faixa espectral sensível aos fotodiodos está entre $380 \mathrm{~nm}$ e $780 \mathrm{~nm}$, com valores de pico máximo em 425, 475, 525, 625, $675 \mathrm{~nm}$ respectivamente. Adicionalmente, o sistema possui uma matriz de fotodiodos sem filtro (PW). Os fotodiodos são conectados diretamente a dois amplificadores integrados de transimpedância com quatro canais programáveis de ganho, tipo MTI04CS, fabricado por MAZeT Company. As seleções de ganho são definidas por 3 bits de entrada de combinação binária do circuito integrado MTI04CS que permite até 8 estágios diferentes de amplificação. Após a amplificação, os sinais oriundos dos fotodiodos são selecionados pelo multiplexador e direcionados para o sistema de amplificador de 
sincronismo (LOCK-IN) que utiliza um ambiente de programação com ferramentas baseadas em instrumentação virtual (NI LabView $\left.{ }^{\circledR}\right)$. Como fonte de luz de excitação foi utilizado um diodo LED, tipo LED600-03, fabricado por Laser Roithner Technik Company com características de comprimento de onda $(\lambda)$ igual a $600 \mathrm{~nm}$, potência de $5 \mathrm{~mW}$ sob condição de corrente constante de $20 \mathrm{~mA}$. O LED foi posicionado frontalmente à cubeta de quartzo e ao sensor multiespectral. A aquisição, controle e processamento de sinais foram realizados através de tecnologia FPGA, com hardware $\mathrm{NI}$ - modelo myRIO-1900, fabricado por National Instruments. A Figura 10 reproduz o diagrama esquemático do sistema portátil multiespectral proposto neste trabalho. Neste sistema os espectros de transmitância são determinados pela medida da corrente dos fotodiodos correspondente a cada banda espectral da matriz do dispositivo (com filtro óptico especifico). A Equação 4 indica a relação de transmitância que é obtida através da detecção do sinal da matriz de fotodiodos.

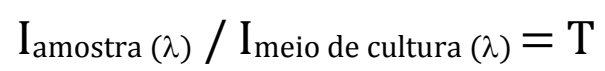

Onde: lamostra representa a corrente de fotodiodos com filtro óptico centrado em $\lambda$ correspondendo a luz transmitida através da amostra de cultura bacteriana e Imeiodecultura é a corrente de fotodiodos com filtro óptico centrado em $\lambda$ correspondendo a luz transmitida através da solução de cultura sem bactérias.

O coeficiente de absorbância é determinado através da Equação 5 .

$$
\operatorname{Abs}(\lambda)=-\log (\mathrm{T}(\lambda))
$$

Para o monitoramento do crescimento microbiano utilizando o sistema portátil multiespectral (Figura 10) proposto, o sistema foi excitado com fonte de luz de comprimento de onda especifico $(I=600 \mathrm{~nm})$ e a detecção do sinal transmitido realizado através da matriz de fotodiodos sem filtro (PW). Esta configuração experimental foi usada porque o biofotômetro comercial também utilizado neste procedimento mede a transmitância ou absorbância em comprimento de onda específico igual a $600 \mathrm{~nm}$. 


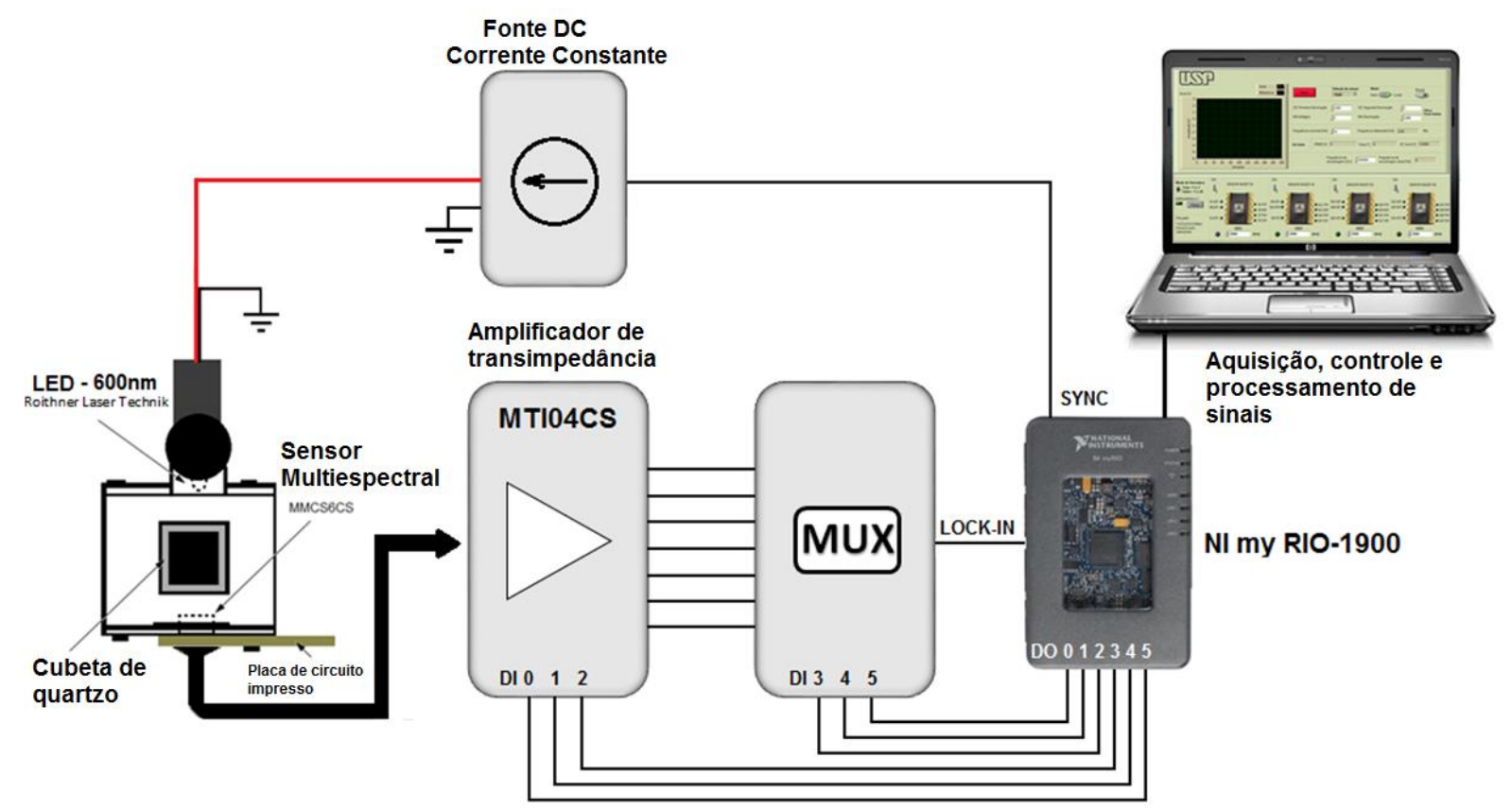

Figura 10 - Sistema multiespectral portátil para monitoramento da taxa de crescimento bacteriano

Para que houvesse uma referência real do processo de crescimento bacteriano, mediu-se diretamente a massa dos microorganismos conforme descrição a seguir. O microorganismo utilizado neste trabalho foi isolado em ambiente e identificado como Enterobacter Cloacae e não tem patogenicidade. O experimento foi realizado em frasco Erlenmeyer de $250 \mathrm{ml}$, previamente esterilizado, com um volume total de ensaio de $100 \mathrm{ml}$. O microorganismo foi apropriadamente inoculado por meio de cultura LB (Luria-Bertani) em incubadora de bancada da Infors HT, modelo Multitron Pro, sob as condições de cultivo de temperatura a $28^{\circ} \mathrm{C}$, e pH de valor igual a 7 com agitação de $180 \mathrm{rpm}$, durante 24 horas. Amostras de $1 \mathrm{ml}$ eram retiradas a cada hora e analisadas em i) Espectrofotômetro Eppendorff (modelo Biofotômetro), em comprimento de onda $(\lambda)$ igual a $600 \mathrm{~nm}$ e ii) Sistema portátil multiespectral proposto neste trabalho.

Para quantificação de biomassa, foram filtrados entre $5 \mathrm{ml}$ e $10 \mathrm{ml}$ de cultura celular com diferentes medidas de absorbância em membrana Milipore $0,22 \mu \mathrm{m}$ utilizando um sistema à vácuo de filtração. As membranas foram previamente secas em forno de microondas doméstico pelo período de 5 minutos, em seguida, foram removidas e arrefecidas em dessecador por 10 minutos e pesadas em balança analítica. Após a filtração, o mesmo procedimento de secagem foi realizado.

A concentração celular foi determinada através da Equação 6 . 


$$
\mathrm{C}_{\text {cel }}=(\mathrm{mf}-\mathrm{mi}) / \mathrm{Vf}
$$

Onde: $\mathbf{C}_{\text {cel }}$ é a concentração celular em miligramas por mililitros; $\mathbf{m f}$ e $\mathbf{m i}$ correspondem a massa pesada antes e após a filtração, em miligramas e Vf é o volume filtrado em mililitros.

A curva de correlação entre os dados de absorção obtidos em $\lambda=600 \mathrm{~nm}$ e os dados de massa seca foi demonstrada. 


\section{Capítulo 4}

\section{RESULTADOS E DISCUSSÕES}

A seguir são apresentados os resultados obtidos com o sistema de detecção de oxigênio dissolvido e os resultados de monitoramento de crescimento bacteriano detalhado nos procedimentos experimentais discutindo os impactos científicos e tecnológicos destes resultados.

\subsection{Sistema de detecção de oxigênio dissolvido.}

A resposta do sensor foi definida pela Equação 7 com a variação da frequência relativa de saída em relação a frequência de referência, que corresponde ao sinal fluorescente do sensor imerso em água sem OD.

$$
\text { resposta }=\frac{\Delta_{\mathrm{f}}}{\mathrm{f}_{\text {ref }}}
$$

Onde: fref representa a intensidade fluorescente vinda do dispositivo sensor imerso em água sem a presença de OD.

Como o fotodetector é composto por quatro matrizes, sendo três com filtros RGB e uma sem filtro, a saída correspondente às matrizes com filtro RGB não apresentou qualquer sinal quando as matrizes são excitadas diretamente por LED, para fotodetectores o sinal de saída obtido das matrizes com filtros RGB está relacionado à emissão da intensidade fluorescente emitida das moléculas de PtOEP. Deste modo, o sistema fotodetector apresentado neste trabalho detecta a emissão fluorescente oriunda da parte sensível do sensor sem a interferência da emissão de luz vinda do diodo LED utilizado para excitação das moléculas corantes de PtOEP.

As curvas de respostas da emissão fluorescente nas matrizes de fotodiodos vermelho, verde e azul (RGB) apresentam duas regiões bem definidas. Na região com baixa 
concentração de OD (0-4 mg/l) as curvas de resposta apresentam características não - lineares, entretanto, na região com alta concentração de OD (4-18 mg/l) o sensor apresentou resposta de comportamento linear para vermelho, verde e azul, respectivamente (Figura 11). Na região linear, a resposta de emissão dos fotodiodos na matriz dos filtros vermelhos foi de maior intensidade seguida pela emissão dos fotodiodos nas matrizes de filtros verde e azul, sendo a emissão na matriz de filtro azul com menor intensidade de reposta. Tal resultado era esperado, uma vez que as moléculas de PTOEP emitem em comprimento de onda de $644 \mathrm{~nm}$, estando, portanto, dentro da faixa específica do cumprimento de onda do vermelho $(625-740 \mathrm{~nm})$ (BRAGA et al., 2015). No entanto, a inclinação de todas as curvas (na região de 4 a $18 \%$ de OD) apresenta praticamente os mesmos valores de 0,012, 0,013 e 0,013/ OD (\%) para emissão nos fotodiodos em matrizes vermelho, verde e azul, respectivamente (Figura 11). Na região de baixa concentração de OD a derivada da curva de resposta (Figura 12) evidencia claramente a característica não-linear da resposta do sensor, uma vez que as derivadas das curvas não são constantes nesta região. A matriz de filtro vermelho de fotodiodos é mais sensível seguidos dos fotodiodos em matriz de filtro verde e filtro azul que apresentou menor sensibilidade entre os três grupos, nesta região.

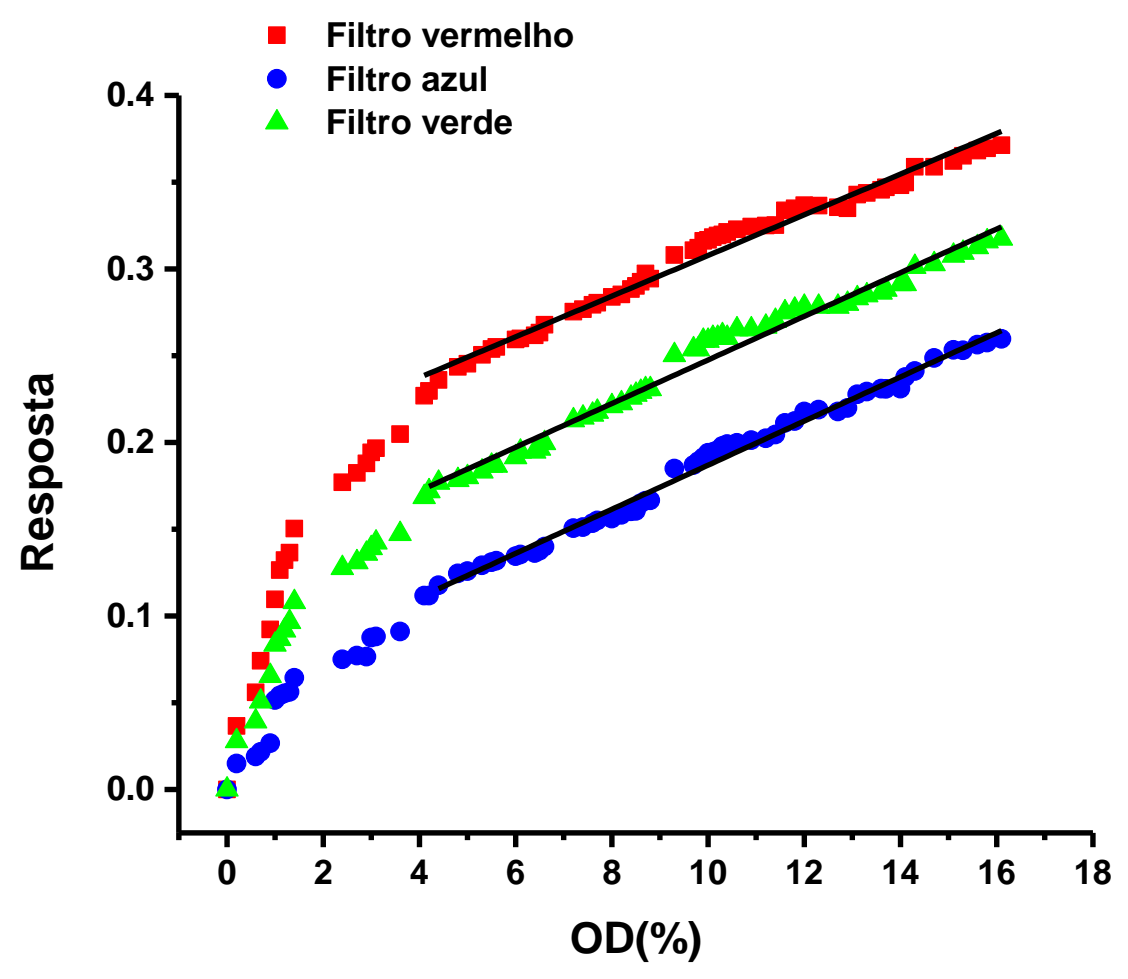


Figura 11 - Curvas de respostas das matrizes de fotodiodos com filtros vermelho, verde e azul em função da concentração de OD.

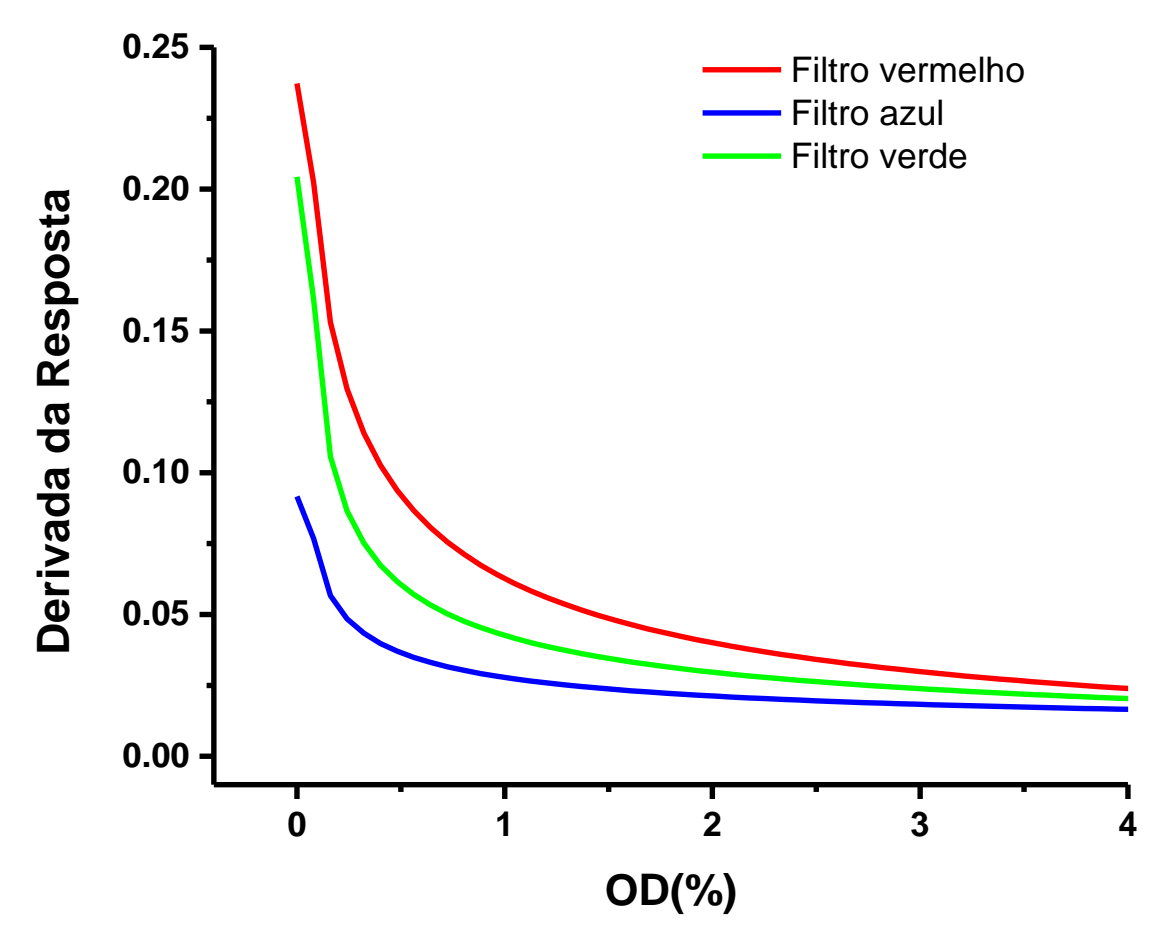

Figura 12 - Derivada das curvas obtidas da curva de resposta (Figura 11) correspondente as matrizes de fotodiodo RGB

A Figura 13 mostra a reposta dinâmica do sensor de fibra óptica. O processo de transição da água sem OD para a água saturada de OD foi rápido (8 s) no entanto, o processo de recuperação foi lento (236 s). Estes resultados são diferentes da resposta dinâmica de um sensor de gás $\mathrm{O}_{2}$ reportado em (SANTOS; SALCEDO, 2014), onde é apresentado $2 \mathrm{~s}$ para tempo de resposta e 3,2 s para tempo de recuperação, mesmo sendo o filme ativo de mesma composição do utilizado neste trabalho (PtOEP-PVC). Portanto, o sensor de fibra óptica para detecção de OD apresentou uma ordem de grandeza maior para resposta e duas ordens de grandeza maior para o tempo de recuperação (em relação ao sensor de gás $\mathrm{O}_{2}$ ). Isto deve-se ao fato de o sensor de OD estar diretamente relacionado ao processo de difusão do gás $\mathrm{O}_{2}$ em meio aquoso, ou seja, este processo é mais lento em água que em ambientes gasosos (CHENGSHANE; YU-LUNG, 2010). Por outro lado, a resposta dinâmica (Figura 13) mostra que o processo de recuperação do sensor sofre um pequeno processo de histerese que poderia ser atribuído a fotodegradação (photobleanching) das moléculas ativas de PtOEP. Em CHENG-SHANE (2010) é relatado um sensor de fibra óptica para 
detecção de OD apresentando tempo de resposta de 130 segundos e processo de recuperação em 694 segundos, tempos muito superiores ao mostrado neste trabalho.

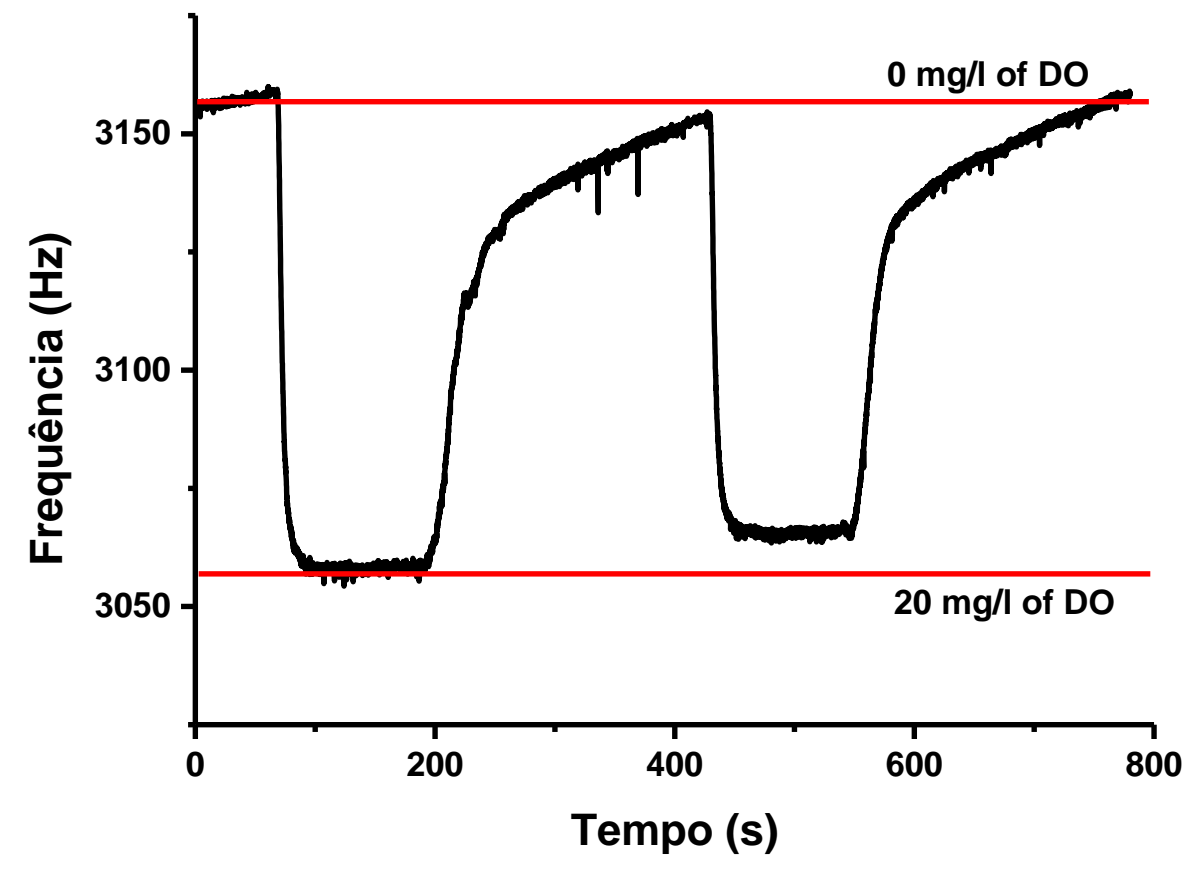

Figura 13 - Resposta dinâmica para o sensor de detecção de OD. 


\subsection{Sistema multiespectral portátil para monitoramento da taxa de crescimento bacteriano}

A Figura 14 mostra a evolução do coeficiente de absorção em função do tempo de cultivo microbianos obtidos através do biofotômetro comercial e sistema portátil multiespectral, respectivamente. A Figura 15 também evidencia a evolução da massa microbiana como função do tempo obtida pela medição direta da massa. Os perfis das curvas mostram a mesma tendência em relação ao tempo.

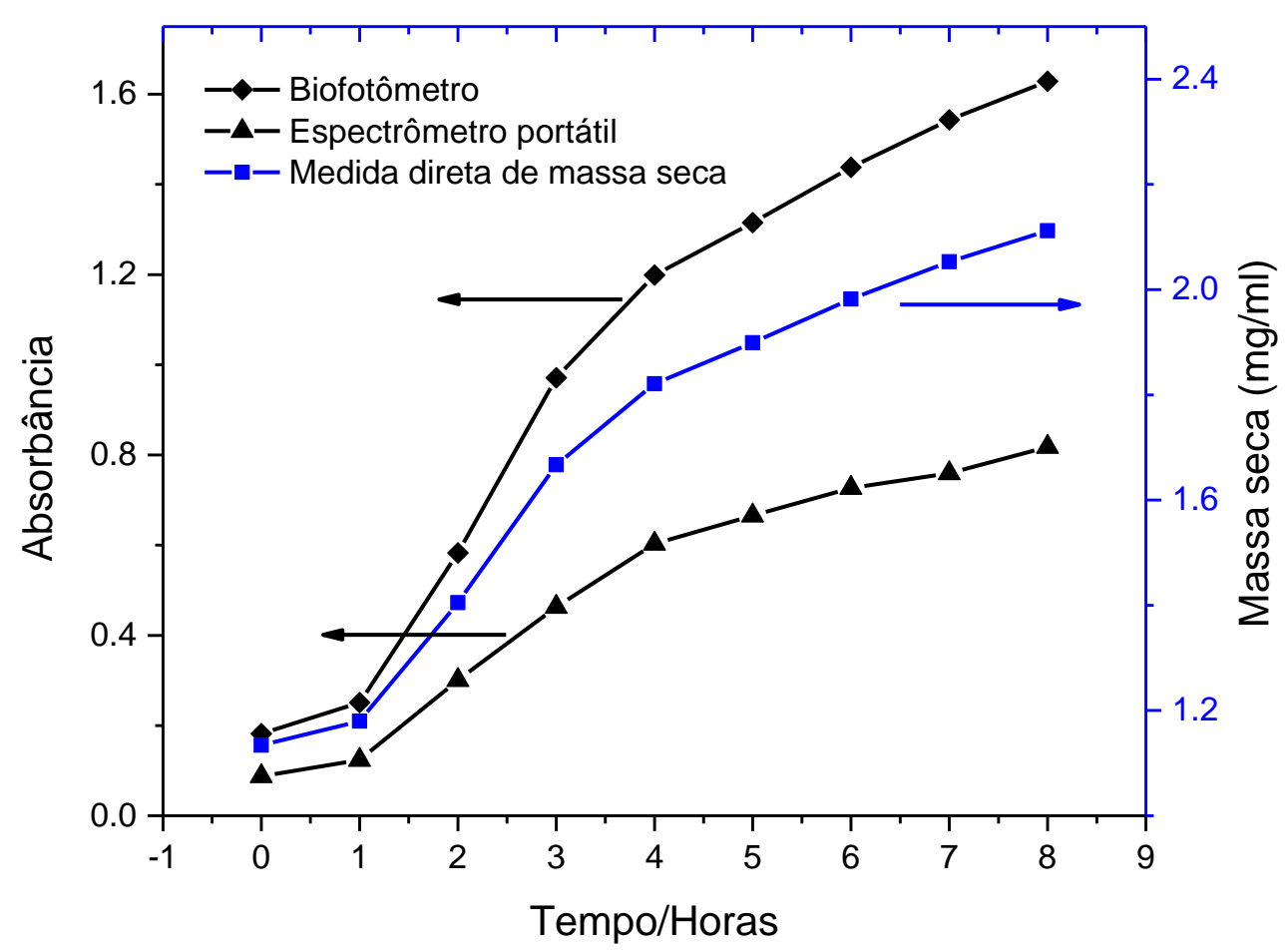

Figura 14 - A evolução do coeficiente de absorção em função do tempo de cultivo bacteriano, obtida através do biofotômetro e do sistema mutiespectral portátil. Como referência também é mostrada a evolução da massa seca bacteriana (medição direta) em função do tempo.

As curvas dos coeficientes de absorção em função da massa seca dos microorganismos apresentam uma dependência linear como pode ser observado na Figura 15. Estes resultados mostram que a evolução do coeficiente de absorção poderia ser utilizada com sucesso para monitoramento da dinâmica de crescimento microbiano, evitando assim o complexo processo de medição de massa. 
As diferentes inclinações das curvas mostradas na Figura 15 estão relacionadas a resolução espectral diferente do biofotômetro e do sistema portátil multiespectral pois a fonte de excitação do biofotômetro possui monocromaticidade mais elevada que a fonte de excitação utilizada no sistema portátil multiespectral. O diodo LED utilizado tem banda de emissão com largura à meia altura em cerca de $20 \mathrm{~nm}$. Contudo, as taxas de crescimento específico ou relativo do microorganismo monitorado neste trabalho, obtidas através das curvas mostradas na Figura 14 possuem quase as mesmas características para todos, conforme será discutido na sequência.

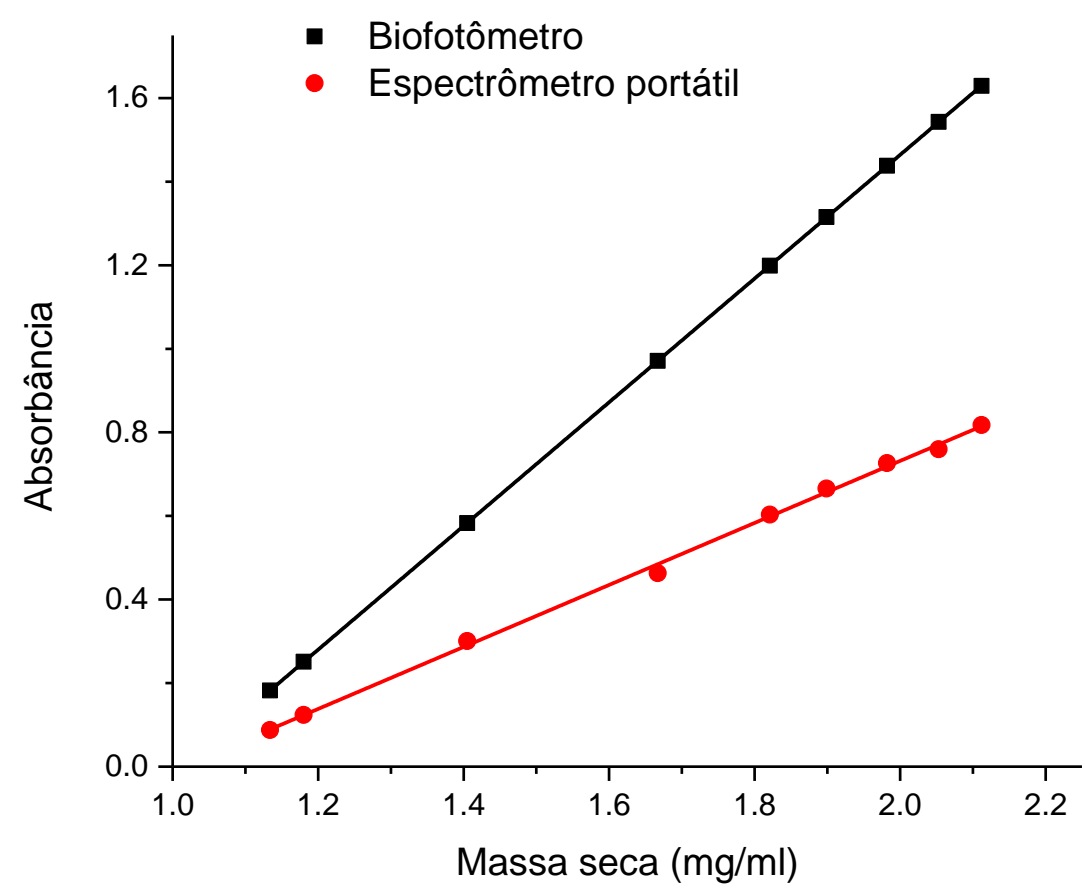

Figura 15 - Gráfico do coeficiente de absorbância em função da massa seca obtida a partir dos dados que foram retratados na Figura 14

A rigor, as curvas apresentadas na Figura 14 mostram inicialmente que a taxa de crescimento microbiano é lenta, este intervalo de tempo é conhecido como fase de latência (lag). Neste intervalo de mudança repentina do ambiente para os microorganismos, o sistema relaxa lentamente para a nova condição, após essa fase de adaptação a taxa de crescimento aumenta até um valor constante (máximo), este processo permanece estacionário até o momento em que a taxa de crescimento começa a diminuir. Esta taxa decrescente pode ser relacionada a diferentes mecanismos como inibição de contato (interação bactéria-bactéria), interação com o ambiente, auto inibição relacionada a mudança de $\mathrm{pH}$ durante o processo de 
crescimento ou a redução dos nutrientes do meio (BARANGI; ROBERTS,1994). A primeira abordagem para esta dinâmica de crescimento é expressa pela Equação 8 (BARANGI; ROBERTS,1994).

$$
\frac{d x}{d t}=u(x) x
$$

Aqui $\mathbf{x}$ é a concentração de microorganismo. A taxa específica de crescimento (taxa relativa) pode ser expressa na Equação 9:

$$
\frac{1}{x} \frac{d x}{d t}=\frac{d \ln (x)}{d t}=u(x)
$$

A função $\mathrm{u}(\mathrm{x})$ na Equação 9 é relacionada aos mecanismos descritos acima que originam um efeito decrescente sobre a taxa de crescimento (dx/dt), assim essa função deveria ser uma função monotônica descrescente da concentração de microrganismos $(\mathrm{x})$. Contudo a taxas de crescimento específico, obtidas pelas curvas na Figura 14, demonstram curvas com máximo (Figura 16), isto é, a função $\mathrm{u}(\mathrm{x})$ não é uma função monotônica decrescente, de modo que a Equação 8 não considera a região de latência no processo de crescimento microbiano. Neste sentido, alguns autores (BARANGI; ROBERTS,1994), sugerem um modelo mais completo para descrever a dinâmica de crescimento acrescentando ao lado direito da equação outra função que considera o processo de latência. A Equação 10 expressa a um modelo mais completo para a dinâmica de crescimento onde a função $\alpha(t)$ relaciona 0 processo de latência (lag) (BARANGI; ROBERTS,1994).

$$
\frac{d x}{d t}=\alpha(t) u(x) x
$$

Isto explica porque $1 / x(\mathrm{~d} x / \mathrm{dt}$ ) (taxa de crescimento específico) como função de $\mathbf{x}$ inicialmente com valor baixo aumenta gradativamente até atingir um valor máximo para em seguida diminuir monotonicamente (Figura 16). É importante mencionar que as taxas de crescimento específico obtidas através do biofotômetro e do sistema portátil multiespectral proposto são muito semelhantes. Já as curvas da taxa 
especifica obtida a partir das medidas de massa seca mostraram-se diferentes, mas apresentando aproximadamente a mesma tendência que as das outras curvas. As curvas na Figura 16 foram obtidas através do ajuste de curvas da Figura 15 com função sigmoide dada pela Equação 11, como previsto na solução da Equação 10 (BARANGI; ROBERTS,1994).

$$
y=\frac{A_{1}-A_{2}}{1+\left(x / x_{0}\right)^{p}}+A_{2}
$$

Em todos os casos o processo de ajuste foi perfeito, isto é, o ajuste da curva passou pelos pontos experimentais. Através deste ajuste é possível determinar a derivada $\mathrm{dx} / \mathrm{dt}$ de forma precisa. Neste ponto nota-se que a taxa de crescimento específico oriunda do biofotômetro e do sistema portátil são muito próximas. Estes resultados evidenciam que o sistema proposto neste trabalho apresentou o mesmo desempenho que o sistema comercial biofotométrico, podendo ainda ser transportado facilmente para qualquer ambiente. Esta portabilidade do sistema multiespectral permite 0 monitoramento da dinâmica de crescimento microbiano em tempo real evitando a coleta de amostras sempre que a concentração de microorganismos for avaliada, tal como ocorre quando a medição é feita utilizando o biofotômetro ou medição direta de massa seca. 


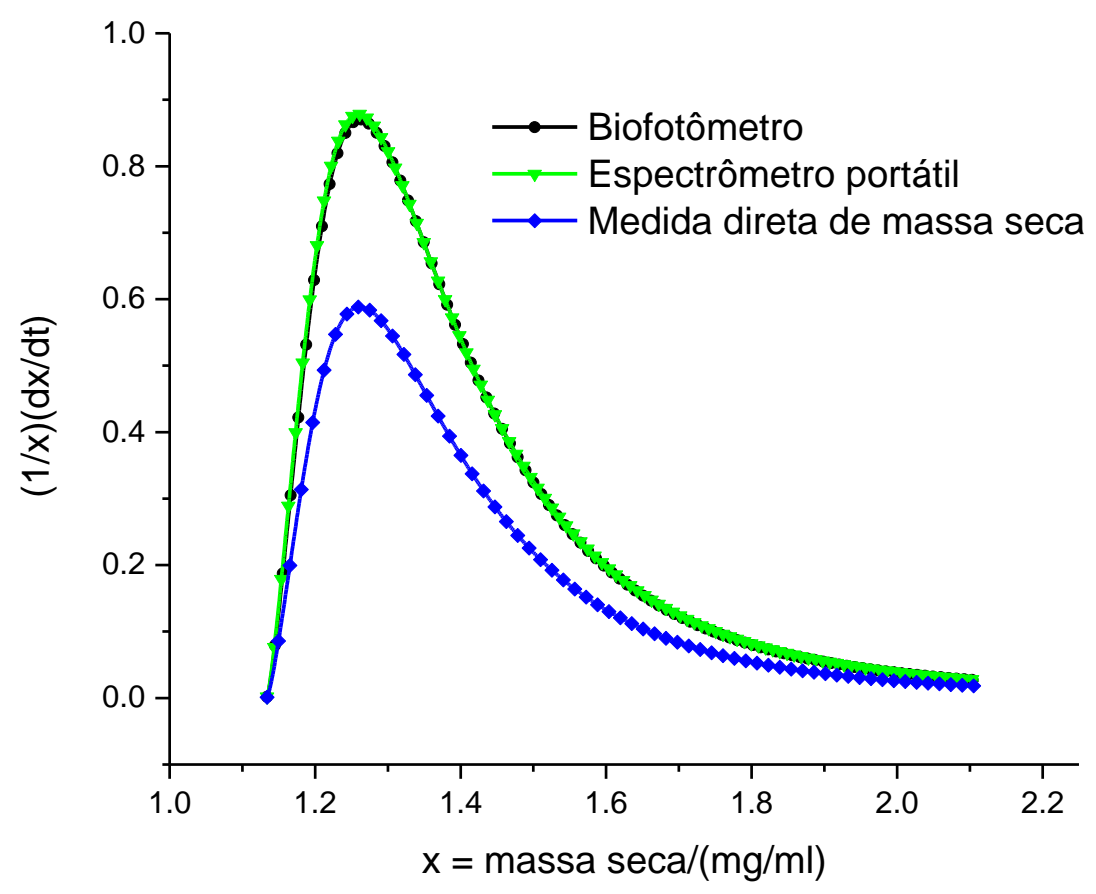

Figura 16 - Taxa de crescimento específico da cultura bacteriana em função da massa seca correspondente aos dados obtidos do biofotômetro, sistema multiespectral portátil e medição direta da massa seca, respectivamente. 


\section{Capítulo 5}

\section{Conclusões}

No presente trabalho foram desenvolvidos dois sistemas portáteis optoeletrônicos utilizados para a deteç̧ão de oxigênio dissolvido (OD) e o monitoramento da taxa de crescimento bacteriano. A flexibilidade dos sistemas propostos permite em adição sua utilização no monitoramento ambiental em sistemas de biorremediação, de lagos, rios e fontes. Outra vantagem dos sistemas em relação aos equipamentos de bancada está relacionada a sua utilização em monitoramento in-situ e em tempo real. Os resultados da resposta do sistema ao monitoramento de $\mathrm{OD}$ em meio aquoso mostraram uma resposta linear na faixa de $4 \mathrm{mg} / \mathrm{l}$ a $18 \mathrm{mg} / \mathrm{l}$ cuja tempo de resposta foi da ordem de $6 \mathrm{~s}$ e tempo de recuperação de $236 \mathrm{~s}$. A resposta dinâmica deste sistema mostrou-se superior aos reportados na literatura. Foi utilizado um circuito integrado de fotodetectores para detecção da fluorescência com saída RGB que mostrou alta compatibilidade com a emissão do diodo LED (utilizado para a excitação das moléculas de PtOEP) e a região do espectro de emissão fluorescente, uma vez que, o filtro RGB atenuou quase que completamente a luz emitida pelo diodo LED (377 nm) permitindo a passagem da luz originária da emissão fluorescente das moléculas de PtOEP (644 nm).

O sistema proposto para monitorar a dinâmica de crescimento de culturas de bactéria baseado em fotodetectores optoeletrônicos integrados, na aquisição, controle e processamento de sinais com tecnologia FPGA utilizando hardware $\mathrm{NI}$ modelo myRIO- 1900, fabricado pela National Instruments mostrou o mesmo desempenho do obtido com um espectrômetro de bancada dedicado para este fim denominado de biofotômetro. Assim, a portabilidade e flexibilidade do sistema proposto mostra-se promissor para o monitoramento da dinâmica de crescimento de bio-culturas in-situ e em tempo real evitando desta forma complexos processos de medição ex-situ. 


\subsection{Trabalhos futuros}

Os resultados atingidos neste trabalho permitem propor o desenvolvimento de sistemas integrados e mais completos na tarefa de monitoração de culturas biológicas. Nesse sentido, por exemplo, os sistemas desenvolvidos neste trabalho poderão ser integrados de tal forma que o sistema multiespectral possa monitorar a taxa de crescimento microbiano pela medição da concentração de oxigênio dissolvido presente no meio e pela medição da turbidez do meio de cultura a partir do espectro de transmitância da cultura. Este novo sistema poderá ser integrado a uma placa eletrônica com tecnologia FPGA (Field Programmable Gate Array) e softwares baseados em instrumentação virtual ( $\mathrm{NI}$ LabView®) para monitoramento em tempo real do crescimento microbiano no meio de cultura. $O$ diagrama esquemático do desenvolvimento deste sistema integrado é mostrado na Figura abaixo:

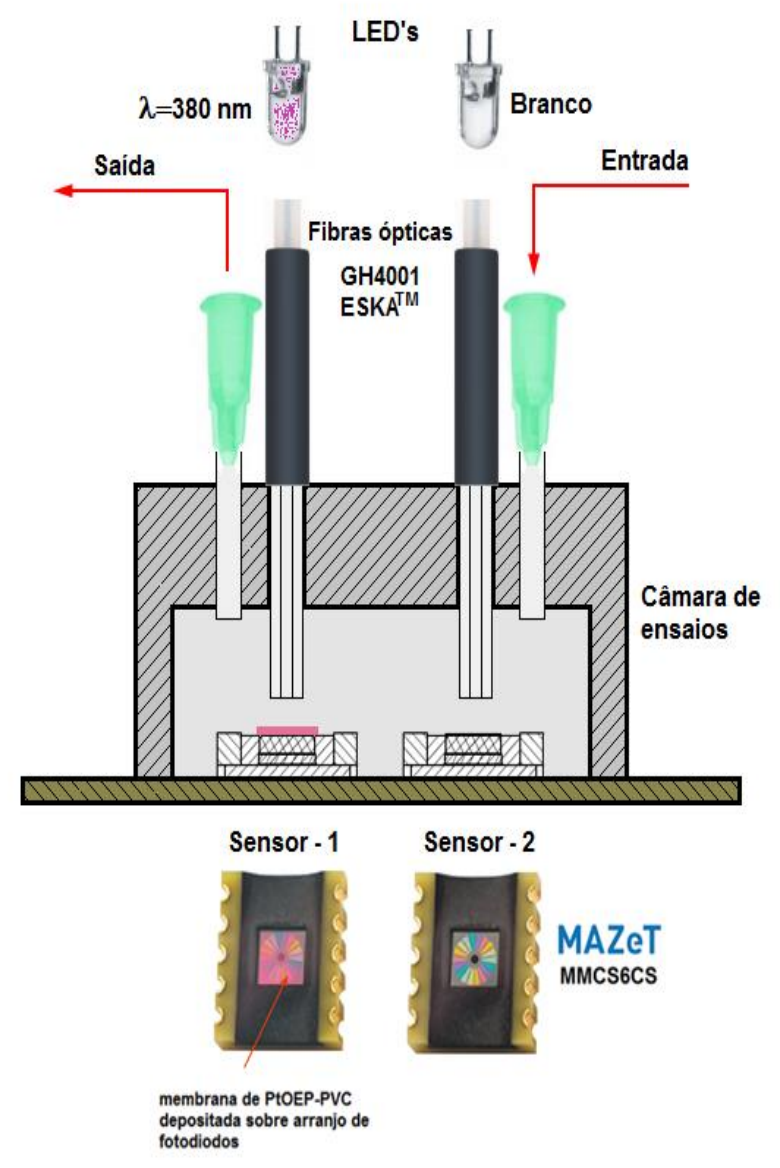

Figura 17 - Diagrama esquemático de um sistema integrado para monitoramento da taxa de crescimento microbiano e oxigênio dissolvido em meio de cultura. 


\subsection{Publicações}

OLIVEIRA, F. C.; BRAGA, M. S.; GONÇALVES, G. M.; SALCEDO, W. J. "Fluorescence based Optical Fiber Sensor for Dissolved Oxygen Detection in Water Media" In: XVI Safety, Health and Environment World Congress (SHEWC'2015), Porto, Portugal.

OLIVEIRA, F. C.; BRAGA, M. S.; CHAMPI, H. A. A.; BORGES, V. F.; BALTAZAR, M. P. G.; SALCEDO, W. J. "Portable Multispectral System for Bacteria Growth Rate Monitoring" In: $32^{\text {nd }}$ Symposium on Microelectronics Technology and Devices ((SBMICRO'2017), Fortaleza, Brasil 


\section{REFERÊNCIAS}

ADAMS, G.O; FUFEYIN, P.T; OKORO, S.E; EHINOMEN, I. " Biostimulation an Bioaugmention: A Review". International Journal of Environmental Bioremediation \& biodegration, vol. 3(1), 2015, pp. 28-39.

ALHO, C.J.S. The Value of Biodiversity, Brazilian Journal of Biology, vol. 68(4),2008, pp.1115-1118

ALTERTHUM, F. Crescimento Microbiano. In:TRABULSI, L. R. Microbiologia. 4edição.São Paulo: Atheneu, 2008,p. 30-35

AMAO, Y. "Probes and Polymers for Optical Sensing of Oxygen", Microchim. Acta, Vol. 143, 2003, pp. 1-12.

BARANGI,J; ROBERTS, T.S. "A dynamic approach to predicting bacterial growth in food", Int. J. of Food Microbiology, vol. 23, 1994, pp. 277-294.

BHARDWAJ, J.; GUPTA, K. K., "A Review of Emerging Trends on Water Quality Measurement" Sensors, 2015 International Conference on Technologies for Sustainable Development (ICTSD-2015), Feb. 04 - 06, 2015, Mumbai, India.

BRAGA, M. S.; BORGES, V. F.; GONÇALVES, G. M.; GOMES O. F.; SALCEDO, W. J. "Sensor óptico multifuncional para detecção de $\mathrm{O}_{2}$ e oxigênio dissolvido". Proceedings of Safety, Health and Environment World Congress, vol. 14, 2014, pp. 309-313.

BRAGA, M.S. Dissertação de Doutorado: Sistemas optoeletrônicos portáteis para detecção de gases, oxigênio dissolvido e de metais pesados aplicados no controle ambiental. Escola Politécnica da USP, 2016.

BRAGA, M.S.; JAIMES, R.F.V.V.; BORYSOW, W.; GOMES, O.F.; SALCEDO, W.J. Portable Multispectral Colorimeter for Metallic Ion Detection and Classification. Sensors, v. 17, 2017, pp. 1730. 
CARPENTER, J., "The accuracy of the Winkler method for dissolved oxygen analysis", Limnology and Oceanography, vol. 10, no. 1, Jan. 1965, pp. 135-140.

CHENG-SHANE Chu, YU-LUNG Lo, Optical fiber dissolved oxygen sensor based on $\mathrm{Pt}$ (II) complex and core-shell silica nanoparticles incorporated with sol-gel matrix, Sensors and Actuators B, Vol. 151,2010, pp. 83-89.

COMPANHIA AMBIENTAL DO ESTADO DE SÃO PAULO. Qualidade das águas superficiais no estado de São Paulo: Relatório. São Paulo: CETESB, 2014 p. 48-52

ELOSUA, C; DE ACHA, N ; TORRES, D.L; MATIAS, I.R; ARREGUI, F.J. Luminescent Optical Fiber Oxygen Sensor following Layer-by-Layer method. Procedia Engineering. vol.87, pp. 987-990, 2014.

GAUR, N.; FLORA, G.; YADAY, M.; TIWARI, A. "A Review with Recent Advancements on Bioremediation Based Abolition of heavy Metals". Environmental Science. Processes \& Impacts, vol. 16(2),2014, pp.180-93.

KENSA, M.V. "Bioremediation an overview", Journal of Industrial Pollution Control, vol.27(2), 2011,pp. 161-168

KUMAR, A; BISHT, B.S; JOSHI, V.D; DHEWA T. " Review on Bioremediation of Polluted Environment: A Management Toll". Vol. 1(6), 2011,pp.1079-1093.

LEE, S-K.; OKURA, I. Photoluminescent determination of oxygen using metalloporphyrin-polymer sensing systems. Spectrochimica Acta, vol.54,1998, p. 91-100, 1998

LEE, E.D; WERNER, T.C; SEITZ, W.R. Luminescence Ratio Indicators for Oxygen. Anal. Chem. vol. 58, 1987, pp. 279-283

LEE, S; PARK, J.W. Luminescent oxygen sensors with highly improved sensitivity based on a porous sensing film with increased oxygen accessibility and photoluminescence. Sensor and Actuators B: Chemical, vol. 249, 2017, pp. 364377. 
MANDIGAN,M.T; MARTINKO, J.M; BENDER, K.S; BUCKLEY, D.H; STAHL, D.A. Crescimento e Controle Microbiano. In: Microbiologia de Brock. $14^{\circ} \mathrm{ed}$. Porto Alegre: Artmed, 2016. cap.5, p.149-158

MICHAEL, J.R.S; UNTERMAN, R. "Evaluating Bioremediation: Distinguishing Fact from Fiction, " Annual Review of Microbiology, vol. 47(1), 1993, pp.715-736

MISRA, H. and FRIDOVICH, I., "A convenient calibration of the Clark oxygen electrode", Analytical Biochemistry, vol. 70, No. 2, Jan. 1976 pp. 632-634.

MOHR, G. J.; WOLFBEIS, O. S. Anal. Chim. Acta 1995, 316, 239.

MONOD, J. " A Certain Number". Annual Reviews in M, vol(XI),1949, pp.371-394.

MCMURRAY, H. N.; DOUGLAS, P.; BUSA, C.; GARLEY, M. S. J. Photochem Photobiol. A: Chem. Vol. 80, 1994, p. 283.

NICHOLLIAN, E.H.; BREWS, J.R. MOS Physics and Technology, New York, Wiley Interscience Publication, 2, 1982.

O'NEILL, K.; SCHREIDER, M.; MCARTHUR, L.; SCHREIDER, S., "Changes in the water quality characteristics during a macroalgal bloom in a coastal lagoon", Ocean \& Coastal Management xxx (2015) 1-5 in Press.

PERPÉTUO, E.A; SOUZA, C.B; NASCIMENTO, C.A.O. Engineering for Bioremediation, Progress in Molecular and Environmental Bioengineering From Analysis and Modeling to Technology Applications. Chapter 28, pp. 605-632, 2011 PULIDO, C.; ESTEBAN, O. "Improved fluorescence signal with tapered polymer optical fibers under side-illumination", Sensors and Actuators B, Vol. 146, 2010, pp. $190-194$.

RAMASAMY, S. M.; HURTUBISE, R. J.,Anal. Chim. Acta, Vol. 152, 1983, p. 83.

RECH, E., 2007. "A biotecnologia, a sustentabilidade e a biodiversidade brasileira". CIB | Conselho de Informações sobre Biotecnologia. Acesso em: http://cib.org.br/estudos-e-artigos/a-biotecnologia-a-sustentabilidade-e-abiodiversidade-brasileira/ 
SANTOS, D. S.; SALCEDO, W. J., "Sistema de processamento de sinais e geração de imagens químicas para sensores LAPS, FMOS, TAOS baseados em dispositivos lógicos programáveis FPGA", Dissertação de mestrado, Escola Politécnica da Universidade de São Paulo, 2014.

SKOOG, D. A.;WEST, D. M.; HOLLER, F. J. "Fundamentals of analytical chemistry" 5th edn. Saunders, Philadelphia, 1988, pp. 344.

TURNER, E. L.; PAUDEL, B.; MONTAGNA, P. A., "Baseline nutrient dynamics in shallow well mixed coastal lagoon with seasonal harmful algal looms and hypoxia formation", Marine Pollution Bulletin xxx (2015) xxx-xxx, in Press.

VAUGHAN, A. V.; BARON, M. G.; Narayanaswamy, R. Anal.Comm.,Vol. 33, 1996, p. 393.

VOLESKY, B. " Detoxification of Metal- Bearing Effluents: Biosorption for the Next Century". Hydrometallurgy, vol 59(2-3),2011, pp. 203-216.

VOLESKY, B. "Biosorption Process Simulation tools". Hydrometallurgy, vol.71(1),2003, pp.551-561.

WARBURTON, P.R; SAWTELLE, R.S; WATSON A.; WANG A.Q. Failure prediction for galvanic oxygen sensor. Sensor and Actuators B: Chemical ,vol 72,pp. 197203,2001.

WIDDEL, F. "Theory and Measurement of Bacterial Growth". Di dalam Grundpraktikum Mikrobiologie, 2007, pp.1-11.

WOLFBEIS, O. S., "Fiber optic" Chemical sensors and biosensors, vol. 2.CRC Press, Boca Raton FL, 1991.

YANG X.; ZHENG Y.; LUO, S.; LIU, Y.; YUAN, L. "Microfluidic in-fiber oxygen sensor derivate from a capillary optical fiber with a ring- shaped waveguide", Sensors and Actuators B, Vol. 182, 2013, pp. 571- 575.

YEH, T.-S; CHU, C.-S; LO, Y.-L. Highly sensitive optical fiber oxygen sensor using $\mathrm{Pt}(\mathrm{II})$ complex embedded in sol-gel matrices. Sensor and Actuators $\mathrm{B}$, vol 119, 2006, pp.701-707 
ZABOCHNICKA-SWIATEK, M; KRZYWONOS, M. " Potentials of Biosorption and Bioacumulation Processes for Heavy Metal Removal". Polish Journal of Environmental Studies, vol. 23(2), 2014, pp.551-561. 